\title{
Performance Evaluation of Hard Rock TBMs considering Operational and Rock Conditions
}

\author{
Xiaoyang Zou $\mathbb{D}^{1},{ }^{1}$ Hui Zheng $\mathbb{D}{ }^{1,2}$ and Yongzhen $M i \mathbb{D}^{2}$ \\ ${ }^{1}$ Shanghai Key Laboratory of Digital Manufacture for Thin-Walled Structures, Shanghai Jiao Tong University, \\ 800 Dongchuan Road, Shanghai 200240, China \\ ${ }^{2}$ Institute of Vibration, Shock and Noise, Shanghai Jiao Tong University, 800 Dongchuan Road, Shanghai 200240, China \\ Correspondence should be addressed to Hui Zheng; huizheng@sjtu.edu.cn
}

Received 7 September 2017; Accepted 10 January 2018; Published 11 March 2018

Academic Editor: Miguel Neves

Copyright (c) 2018 Xiaoyang Zou et al. This is an open access article distributed under the Creative Commons Attribution License, which permits unrestricted use, distribution, and reproduction in any medium, provided the original work is properly cited.

\begin{abstract}
This paper focuses on studying the correlations of the performance of hard rock tunnel boring machines (TBMs) with operational and rock conditions. Firstly, a rigid-flexible coupled multibody dynamic model of an opening hard rock TBM is established for the analysis of its vibration. Then four performance indexes including mean vibration energy dissipation rate, dynamic specific energy (DSE), disc cutter wear rate, and load sharing coefficient are introduced and formulated, respectively, for evaluating the vibration level, excavation energy efficiency, cutter's vulnerability to wear, and load transmission performance of cutterhead driving system of the TBM. Finally, numerical simulation results of the TBM tunneling performance evaluation are obtained and validated by on-site vibration measurement and tunneling data collection. It is found that operational and rock conditions exert important impact on TBM vibration level, excavation energy efficiency, and structure damage. When the type of rock to be cut changes from soft to hard with operational parameters held constant, TBM performance evaluated by these three indexes deteriorates significantly, and both the decrease of excavation energy efficiency and the increase of cutter wear rate caused by TBM vibration are obvious. This study provides the foundation for a more comprehensive evaluation of TBM performance in actual tunneling process.
\end{abstract}

\section{Introduction}

With excellent capacity to cut rock up to $300 \mathrm{MPa}$, hard rock tunnel boring machines (TBMs) have been widely used in today's tunnel excavation [1]. To explore the realistic cutter-rock interaction and its characteristics, various in situ measurements of cutter forces on TBM have been carried out. Early measurements with strain gauges boned on the cutter shaft indicated that the main energy components of cutter forces lie in the frequency range below $10 \mathrm{~Hz}$ [2]. Some years later, measurements considering force-coupling revealed the cutter forces of the front cutter are much larger than the respective forces of the gauge cutter $[3,4]$. The tunneling quality such as the relationship between normal force and rock fracture crack length and the energy utilization in static and dynamic loadings were investigated based on these measurements results $[4,5]$. Recently, the measurements with sensors placed in the cutter saddle show the cutting force varies temporally and spatially even for the same cutter in actual tunneling $[6,7]$. These works are beneficial for the TBM dynamic modeling and performance evaluation. Owning to complex TBM-rock interactions, the rock cutting force loaded by disc cutter is nonlinear and irregular and oscillates violently $[2,3,7,8]$. Under multipoint impact excitation from cutters, TBM vibrates strongly, premature failure of cutters and serious damage in cutterhead driving system occur frequently, and excavation energy efficiency declines, resulting in the increase of tunneling project expense $[8,9]$. There is no doubt that these sufferings of TBM performance have a close correlation with TBM-rock interactions. For an actual tunneling project, one of the major concerns is how the TBM performance evaluated from the aspects of vibration level, excavation energy efficiency, cutter's vulnerability to wear, and load transmission performance of cutterhead driving system changes with operational and rock conditions.

On the issue of TBM vibration, the dynamic characteristics of the cutterhead driving system with a joint cutterhead panel were investigated based on a multi-degree of freedom 
(MDOF) model [10]. Later, the vibration investigation was extended to TBM main system which was modeled using lumped parameter method [9]. Recently, this investigation was pushed forward by establishing a rigid-flexible coupled multibody dynamic model of an opening hard rock TBM [11]. In an investigation performed [11], the bottom shieldrock mass interaction was studied in detail. Nevertheless, the vibration level of the whole TBM varying with operational and rock conditions is still needed to be systematically studied.

Specific energy (SE), defined by energy consumed in cutting a unit volume of rock, has been widely applied to the performance evaluation of the rock cutting by disc cutter. The variation of SE was predicted for TBM operation in a hard and brittle crystalline rock of moderate strength with cutting tests [12]. The SE of rock cutting was evaluated for different geological and operational parameters by numerical simulation, of which the results were comparable with those of cutting tests [13, 14]. As is indicated in [15], energy efficiency is low in dynamic rock cutting because a large amount of energy is carried away by reflected stress wave and transmitted stress wave. In TBM tunneling process, the energy carried by the reflected wave could be a major excitation source of TBM vibration, but it is not considered in the calculation of current SE, which results in a less accurate prediction of excavation energy efficiency in the case of serious vibration of TBM. Therefore, the energy dissipated due to TBM vibration should be considered when the change of the energy efficiency with operational and rock conditions is to be investigated.

The expenditure on disc cutter is at least one-fifth of the project cost and the time spent on replacing the cutter constitutes is about one-third of the total project time, which means that cutter failure is one of the major topics in TBM tunneling [16]. As is the main cause of cutter failure, cutter wear statistically caused $78 \%$ of the total consumed cutters in some TBM tunneling projects [17]. Therefore, cutter wear has been predicted in a number of studies for improving TBM performance in the past years [18]. SE was used to predict the average wear extent of all disc cutters $[16,18]$. A model of disc cutter wear rate was built [19]. Later, a modified model for the evaluation of cutter wear rate considering the influence of vibration was developed [20]. Based on this modified model, it is possible to further evaluate cutter's vulnerability to wear considering the operational and rock conditions.

The load transmission performance of multiple pinionsgear ring meshing was evaluated for TBM's cutterhead driving system by load sharing index considering meshing frequency, bearing stiffness, and mounting locations of pinions [21]. In [22], the load transmission was investigated by load sharing coefficient considering bending-torsional coupling of pinions. Generally, the large load sharing coefficient means poor load transmission performance and serious uneven loading conditions on pinions which easily cause structure damage such as tooth fracture and broken shaft of pinions. In the published works, there is a lack of investigation of the correlation of load transmission performance with operational and rock conditions.

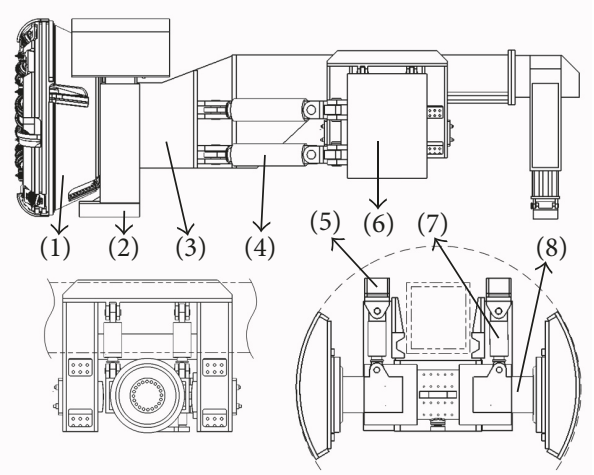

FIGURE 1: Schematics of an opening hard rock TBM. (1) Cutter head. (2) Shield. (3) Main beam. (4) Thrust cylinder. (5) Saddle. (6) Shoe. (7) Torque cylinder. (8) Support cylinder.

This paper presents a study of TBM performance evaluation considering operational and rock conditions from the aspects of vibration level, energy efficiency, cutter wear, and load transmission performance of cutterhead driving system. Following a statement of the problem to be investigated, a rigid-flexible coupled multibody dynamic model of an opening hard rock TBM is established for the vibration analysis of TBM. To deal with the performance evaluation problem, four indexes, namely, mean vibration energy dissipation rate, dynamic specific energy (DSE), disc cutter wear rate, and load sharing coefficient, are then introduced and formulated, respectively. Finally, numerical simulations are performed to obtain the results of the TBM performance varying with operational and rock conditions. The obtained numerical results are further validated through comparing with those from on-site vibration measurement and collected tunneling data.

\section{Modeling of Hard Rock TBMs}

2.1. Dynamic Model of Opening Hard Rock TBMs. An opening hard rock TBM consists essentially of a cutterhead driving system and a hydraulic thrust system, as shown in Figure 1. In rock cutting process, the cutterhead rotates and moves ahead simultaneously, and consequently rock on tunnel face spalls continuously under cutting forces. The opening hard rock TBM is a multibody system. Taking the main components, the connection between them, and the TBM-rock interactions into consideration, a rigid-flexible coupled dynamic model of TBM is established and shown in Figure 2.

In Figure 2, $O X Y Z$ is a global coordinate system, where $Z$ is tunneling direction, $Y$ is vertical direction, and $X$ is determined by right-hand rule. $O_{i} X_{i} Y_{i} Z_{i}(i=1, \ldots, 13)$ are local coordinate systems which are established at the centroid of the corresponding substructures and parallel to $O X Y Z$ at initial time. The main components in Figure 2 are modeled as rigid-flexible coupled structures. $\mathbf{M}_{i}(i=1, \ldots, 13)$ are the corresponding mass matrix. The bending-torsional coupling of each pinion is considered, with $m_{p i}$ and $I_{p i}(i=$ $1, \ldots, N)$ denoting the equivalent mass and inertial moment, 

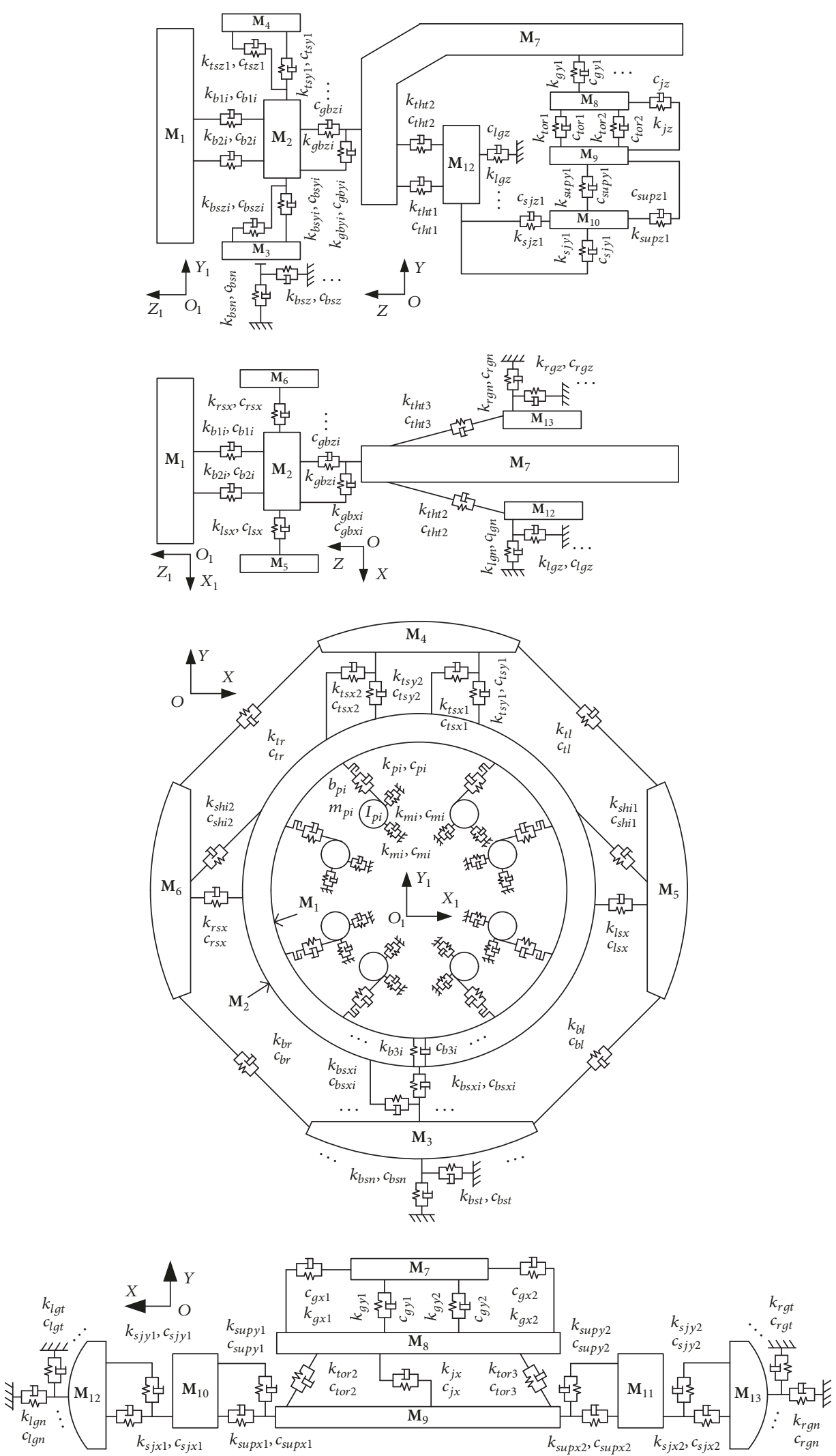

Figure 2: Dynamic model of an opening hard rock TBM. (1) Cutter head. (2) Gearbox. (3) Bottom shield. (4) Top shield. (5) Left shield. (6) Right shield. (7) Main beam assembly. (8) Saddle. (9) Support cylinder body. (10) Left cylinder rod. (11) Right cylinder rock. (12) Left shoe. (13) Right shoe. 
respectively. The dynamic equations of TBM vibration are derived using Newton-Euler method as follows.

The generalized displacement (i.e., the generalized DOFs) vectors of substructures are written as

$$
\begin{aligned}
& \boldsymbol{\psi}_{i}=\left(\mathbf{x}_{i}^{\mathrm{T}}, \boldsymbol{\alpha}_{i}^{\mathrm{T}}, \boldsymbol{\eta}_{i}^{\mathrm{T}}\right)^{\mathrm{T}}, \\
& \mathbf{x}_{i}=\left(x_{i}, y_{i}, z_{i}\right)^{\mathrm{T}}, \boldsymbol{\alpha}_{i}=\left(\alpha_{i}, \beta_{i}, \gamma_{i}\right)^{\mathrm{T}}, \boldsymbol{\eta}_{i}=\left(\eta_{i 1}, \ldots, \eta_{i N_{i}}\right)^{\mathrm{T}},
\end{aligned}
$$

where $\boldsymbol{\eta}_{i}$ is the coefficient vector related to structural elastic mode matrix $\Phi_{i}$; T denoted the transpose of matrix or vector. The dynamic equations of TBM are derived in matrix form as

$$
\mathbf{M} \ddot{\psi}+\mathbf{C} \dot{\psi}+\mathbf{K} \psi=\mathbf{f}_{1}+\mathbf{f}_{2}
$$

with

$$
\begin{aligned}
& \psi=\left(\ldots, x_{p i}, y_{p i}, \theta_{p i}, \ldots, \psi_{1}^{\mathrm{T}}, \ldots, \psi_{13}^{\mathrm{T}}\right)^{\mathrm{T}} \\
& \mathbf{M}=\operatorname{diag}\left(\ldots, m_{p i}, m_{p i}, I_{p i}, \ldots, \mathbf{M}_{1}, \ldots, \mathbf{M}_{13}\right) \\
& \mathbf{M}_{i}=\sum \boldsymbol{\Gamma}_{i}^{\mathrm{T}} m_{i} \boldsymbol{\Gamma}_{i}=\left[\begin{array}{ccc}
\mathbf{M}_{i 11} & \mathbf{M}_{i 12} & \mathbf{M}_{i 13} \\
& \mathbf{M}_{i 22} & \mathbf{M}_{i 23} \\
\text { symmetric } & & \mathbf{M}_{i 33}
\end{array}\right] \\
& \mathbf{K}=\left[\begin{array}{ccc}
\ddots & & \\
& \mathbf{K}_{i j}+\delta_{i j} \mathbf{k}_{i}^{b} & \\
\text { symmetric } & & \ddots
\end{array}\right] \\
& \mathbf{C}=\left[\begin{array}{ccc}
\ddots & & \\
& \mathbf{C}_{i j}+\delta_{i j} \mathbf{c}_{i}^{b} & \\
\text { symmetric } & & \ddots
\end{array}\right] \\
& \mathbf{K}_{i j}=\sum \boldsymbol{\Gamma}_{i}^{\mathrm{T}} k_{i} \mathbf{e}_{X_{i}} \mathbf{e}_{X_{i}} \boldsymbol{\Gamma}_{j} \\
& \mathbf{C}_{i j}=\sum \boldsymbol{\Gamma}_{i}^{\mathrm{T}} c_{i} \mathbf{e}_{X_{i}} \mathbf{e}_{X_{i}} \boldsymbol{\Gamma}_{j} \\
& \boldsymbol{\Gamma}_{i}=\left[\begin{array}{lll}
\mathbf{I} & \left.\mathbf{A}^{r b_{i}} \mathbf{R}_{\left(\mathbf{u}_{0 X_{i}}^{b}\right.}^{\mathrm{T}}+\boldsymbol{\rho}_{X_{i}}^{b}\right) & \mathbf{A}^{r b_{i}} \boldsymbol{\Phi}_{i}
\end{array}\right] \\
& \mathbf{k}_{i}^{b}=\operatorname{diag}\left(0_{1 \times 6}, \omega_{i 1}^{2}, \ldots, \omega_{i N_{i}}^{2}\right) \\
& \mathbf{c}_{i}^{b}=\operatorname{diag}\left(0_{1 \times 6}, 2 \zeta_{i 1} \omega_{i 1}, \ldots, 2 \zeta_{i N_{i}} \omega_{i N_{i}}\right) \\
& \delta_{i j}= \begin{cases}1 & i=j \\
0 & i \neq j\end{cases} \\
& \mathbf{f}_{1}=\left(\ldots, 0,0,0, \ldots, \mathbf{f}_{11}^{\mathrm{T}}, \ldots, \mathbf{f}_{131}^{\mathrm{T}}\right)^{\mathrm{T}} \\
& \mathbf{f}_{2}=\left(\ldots,-F_{p i x},-F_{p i y},-R_{p i} F_{p i}, \ldots, \mathbf{f}_{12}^{\mathrm{T}}, \ldots, \mathbf{f}_{132}^{\mathrm{T}}\right)^{\mathrm{T}} \\
& \mathbf{A}^{r b_{1}}=\left[\begin{array}{ccc}
\cos (\theta) & -\sin (\theta) & 0 \\
\sin (\theta) & \cos (\theta) & 0 \\
0 & 0 & 1
\end{array}\right] \\
& \mathbf{A}^{r b_{i}}=\mathbf{I}, \quad(i=2, \ldots, 13)
\end{aligned}
$$

$$
\mathbf{R}_{\mathbf{v}}=\left[\begin{array}{ccc}
0 & -\mathbf{v}(3) & \mathbf{v}(2) \\
\mathbf{v}(3) & 0 & -\mathbf{v}(1) \\
-\mathbf{v}(2) & \mathbf{v}(1) & 0
\end{array}\right]
$$

where $\mathbf{M}, \mathbf{K}$, and $\mathbf{C}$ are mass matrix, stiffness matrix, and damping matrix, respectively, diag denotes diagonal matrix, $\omega_{i j}$ is natural circular frequency, $\zeta_{i j}$ is modal damping factor with the value of 0.01 used in this simulation, $\mathbf{u}_{0}$ is static deformation vector in steady motion, $\boldsymbol{\rho}$ is the relative vector of point $X_{i}$ on substructure, $\mathbf{I}$ is a third-order unit matrix, $\mathbf{R}_{\mathbf{v}}$ is a matrix formed from coordinate vector $\mathbf{v}, \mathbf{A}^{r b_{i}}$ is direction cosine matrix, and $\mathbf{e}$ is a unit vector denoting the direction of damping spring which connects substructures in system OXYZ [23]. During steady state TBM tunneling, cutterhead rotates around $z$-axis at a constant rotational velocity and $\theta$ denotes the rotational angle. Other substructures have no rotation and their directional cosine matrix are third-order unit matrices. $\mathbf{M}_{i 11}, \mathbf{M}_{i 22}$, and $\mathbf{M}_{i 33}$ are the mass matrices for translational, rotational, and elastic vibrations, respectively. $\mathbf{M}_{i 12}, \mathbf{M}_{i 13}$, and $\mathbf{M}_{i 23}$ are the coupled mass matrices between translational, rotational, and elastic vibrations, respectively. The elastic modes, natural frequencies, and the discretized mass $m_{i}$ can be obtained by using commercial finite element code. It should be noted that the modes of each substructure are obtained under free boundary conditions; thus the first six modes are rigid body movement modes with natural frequency of $0 \mathrm{~Hz}$, resulting in the fact that the first six entries in $\mathbf{k}_{i}^{b}$ and $\mathbf{c}_{i}^{b}$ are zeros. Furthermore, for a fixed point on substructure, its modes are obtained in local coordinate system of the substructure at initial attitude; thus its mode matrix $\Gamma_{i}$ measured in $O X Y Z$ will change with attitude of the substructure. Vector $\mathbf{f}_{1}$ denotes inertial forces arising due to MDOF rotation. Due to very low rotation velocity of cutterhead in practice, the inertial forces are small and thus ignored in this simulation. Vector $\mathbf{f}_{2}$ denotes exciting forces including nonlinear time-varying multiple pinionsgear ring meshing forces, cutter-rock interaction forces, and bottom shield-rock mass contact forces. Meshing forces $F_{p i}$ and the values of structural parameters including equivalent stiffness and damping can be obtained by empirical formulas or finite element analysis as well as those recommended in [11].

2.2. TBM-Rock Interactions. TBM-rock interactions including disc cutter-rock interaction and bottom shield-rock mass nonlinear contact are mainly responsible for the vibration of TBM. These interactions correlate with a number of factors such as geotechnical parameters, cutter geometry, indentation, cutterhead rotation speed, and distribution of cutters on cutterhead $[4,8]$. The asymmetric distribution of cutter easily results in large side force and further leads to strong vibration of TBM in the direction perpendicular to the axis of the tunnel [4]. Similar to earth drilling described in [24], rock cutting by disc cutters makes TBM suffer from vibration due to regenerative effect, that is, the dependence of penetration on the history of cutter motion in cutting process. For a TBM, because of the quasihelical motion of cutter, 


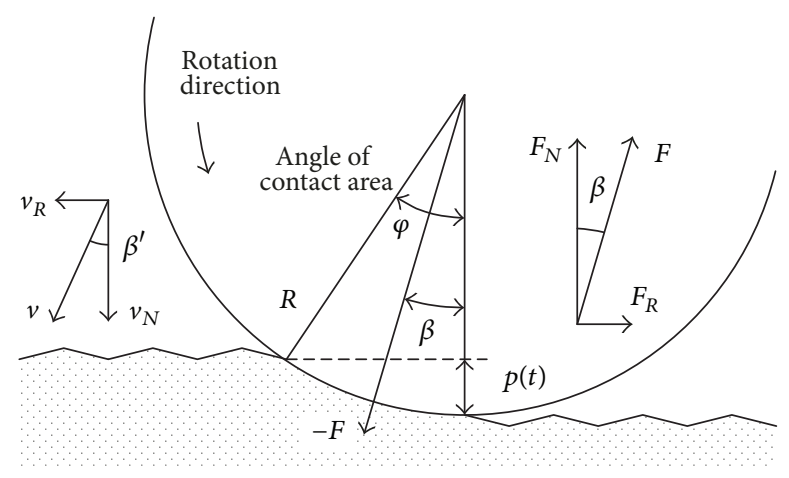

FIGURE 3: Generalized illustration of cutter-rock interaction.

the instantaneous cutter penetration is determined by the current position and the position of the cutter at the previous revolution of cutterhead. Disc cutter-rock interaction is illustrated in Figure 3. Cutter forces can be calculated using the model of Colorado School of Mines (CSM) which has been successfully applied to TBM design and performance evaluation [25]. Considering the varying cutter penetration and even the loss of contact between cutter and rock when cutter penetration is not positive or cutter moves away from rock under vibration conditions, disc cutter force in dynamic rock cutting process can be expressed through modifying the formula given in [25] as

$$
\begin{aligned}
F & =C T R \varphi \sqrt[3]{\frac{\sigma_{c}^{2} \sigma_{t} S}{\varphi \sqrt{R T}}} H(p) H(d) \\
F_{N} & =F \cos (\beta), \\
F_{R} & =F \sin (\beta)
\end{aligned}
$$

with

$$
\begin{aligned}
\varphi & =\cos ^{-1}\left(\frac{R-p}{R}\right), \\
\beta & =\frac{\varphi}{2}, \\
H(y) & = \begin{cases}1 & y \geq 0 \\
0 & y<0\end{cases} \\
p & =z(t)-z(t-\tau), \quad \tau=\frac{2 \pi}{\Omega_{0}} \\
d & =v_{N} \cos (\beta)+v_{R} \sin (\beta),
\end{aligned}
$$

where $F_{N}$ is normal force, $F_{R}$ is rolling force, $C$ is a constant equal to 2.12 according to [25], $T$ is cutter tip width, $R$ is cutter radius, $\sigma_{c}$ is uniaxial compressive strength of rock (UCS), $\sigma_{t}$ is Brazilian indirect tensile strength of rock (BTS), $S$ is cut spacing, $\varphi$ is angle of the contact area, $p$ is cutter penetration, $H(\cdot)$ is the Heaviside function, $z$ is the position of cutter in normal direction, $\tau$ is time delay, and $v_{N}$ and $v_{R}$ are the velocity of cutter center in normal and that in rolling direction, respectively. Due to the regenerative effect in rock cutting, after integrating (4) into (2), delay differential equations are obtained. Because (2) are the differential equations about the generalized displacements measured with modal coordinates, the forces in (4) should be converted into generalized forces through left multiplying the transpose of the mode matrix $\boldsymbol{\Gamma}_{i}$ corresponding to the force point on cutterhead and then be added to vector $\mathbf{f}_{2}$.

The bottom shield-rock mass contact is considered in the dynamic modeling of the TBM. Shield slides on rock mass along tunneling direction when bottom shield-rock mass is in frictional contact, but this state transits to stick when the velocity vanishes due to vibration, and vice versa. Even in more serious vibration, bottom shield-rock mass contact separates, thus introducing discontinuities in TBM dynamic model. Rock mass serves as a support and can be modeled as a Winkler foundation, with damping springs uniformly distributed in both normal direction and tangential direction of shield circumference [26]. In tunneling direction, whether bottom shield is in friction or not should be determined by its motion state.

The equivalent normal and tangential distributed stiffness of Winkler foundation can be obtained by [26]

$$
\begin{aligned}
& k_{n}=\frac{E_{r}}{R_{r}(1+v)}, \\
& k_{t}=k_{z}=\frac{k_{n}}{3},
\end{aligned}
$$

where $E_{r}$ is Young's modulus of the ground, $R_{r}$ is tunnel radius, $v$ is Poisson's ratio which is 0.3 in this study. Considering the state transition of bottom shield and the separation of bottom shield-rock mass contact, the distributed forces in bottom shield-rock mass interaction are obtained as

$$
\begin{aligned}
& F_{s n}=-\left(k_{n}\left(x_{n}+\delta_{0}\right)+c_{n} \dot{x}_{n}\right) H\left(x_{n}+\delta_{0}\right) \\
& F_{s t}=-\left(k_{t} x_{t}+c_{t} \dot{x}_{t}\right) H\left(x_{n}+\delta_{0}\right) \\
& F_{s z} \\
& = \begin{cases}-\left(k_{z} x_{z}+c_{z} \dot{x}_{z}\right) H\left(x_{n}+\delta_{0}\right) & -\left(k_{z} x_{z}+c_{z} \dot{x}_{z}\right)<\mu\left(\dot{x}_{z}\right) F_{s n} \\
\mu\left(\dot{x}_{z}\right) F_{s n} & -\left(k_{z} x_{z}+c_{z} \dot{x}_{z}\right) \geq \mu\left(\dot{x}_{z}\right) F_{s n},\end{cases}
\end{aligned}
$$

where $x_{n}, x_{t}$, and $x_{z}$ are the displacements of contact point in normal, tangential, and tunneling direction, respectively, $\delta_{0}$ is 
the initial compression of normal spring due to TBM gravity, and $\mu$ is a velocity related frictional coefficient. According to [20], $\mu$ is taken as $\mu=0.15-0.30$ for kinetic coefficient and $\mu=$ $0.25-0.45$ for static coefficient. To reduce the computational difficulty due to discontinuity brought by bottom shield's stick-slip state, a smooth representation of $\mu$ with velocityweakening law is adopted and expressed as

$$
\begin{aligned}
& \mu\left(\dot{x}_{z}\right) \\
& \quad=\frac{2}{\pi} \arctan \left(\varepsilon \dot{x}_{z}\right)\left(\mu_{k}+\left(\mu_{s}-\mu_{k}\right) \exp \left(-\lambda\left|\dot{x}_{z}\right|\right)\right),
\end{aligned}
$$

where $\mu_{k}$ is kinetic coefficient, $\mu_{s}$ is static coefficient, $\varepsilon$ is a smooth coefficient, and $\lambda$ is a characteristic coefficient.

\section{Performance Evaluation Indexes for Hard Rock TBMs}

3.1. Mean Vibration Energy Dissipation Rate. Mean vibration energy dissipation rate $u$ is equivalent to the energy dissipated due to TBM vibration in a unit time. It is calculated by

$$
u=\frac{W_{d}}{t_{2}-t_{1}}
$$

with

$$
W_{d}=\int_{t_{1}}^{t_{2}}\left(\dot{\psi}^{\mathrm{T}} \mathbf{C} \dot{\psi}+\mathbf{v}_{f}^{\mathrm{T}} \mathbf{F}_{f}\right) \mathrm{d} t
$$

where $W_{d}$ is the energy dissipated due to TBM vibration in a time period, $\mathbf{C}$ is the damping matrix in (2), $\mathbf{F}_{f}$ is a column vector formed by friction forces of all contact points on the bottom shield-rock mass interface, and $\mathbf{v}_{f}$ is the corresponding velocity column vector. Mean vibration energy dissipation rate $u$ is equivalent to a quadratic form of vibration velocity and thus is similar to the square of vibration severity. Vibration severity is the root mean square (RMS) of vibration velocity and used as a traditional assessment of vibration level. Therefore, $u$ is suitable for the evaluation of vibration level of the whole TBM.

3.2. Dynamic Specific Energy. Specific energy (SE) is the energy consumed in cutting a unit volume of rock and has been widely used to evaluate the cutting energy efficiency of a TBM disc cutter. The calculation of the current SE using mean cutting force eliminates the consideration of influence of vibration $[13,14]$. Therefore, it is less accurate for evaluating the realistic excavation energy efficiency of TBM particularly when it undergoes serious vibration. Taking both the energy consumed in rock cutting and the energy dissipated by TBM vibration into account, a new index called dynamic specific energy (DSE) is proposed and defined as

$$
\mathrm{DSE}=\frac{F_{0} L_{0}+W_{d}}{V_{d}}
$$

with

$$
\begin{aligned}
F_{0} L_{0} & =\sum_{i=1}^{N_{c}}\left(F_{i N 0} Z_{N 0}+F_{i R 0} R_{i} \theta\right)+\iint_{\Gamma} F_{s z 0} Z_{N 0} \mathrm{~d} \Gamma \\
V_{d} & =\sum_{i=1}^{N_{c}} \int_{t_{1}}^{t_{2}} R_{i} \theta S p_{i} H\left(p_{i}\right) \mathrm{d} t,
\end{aligned}
$$

where $F_{i N 0}$ and $F_{i R 0}$ are mean normal force and mean rolling force on the $i$ th cutter, respectively, $N_{c}$ is the number of cutters, $\Gamma$ is contact area between shield and rock mass, $R_{i}$ is the radius where the cutter mounted on the cutterhead, $\theta$ is the rotation angle of cutterhead, $S$ is the cut spacing, $p_{i}$ is cutter penetration of the $i$ th cutter, and $H(\cdot)$ is the Heaviside function.

3.3. Disc Cutter Wear Rate. Disc cutter wear is the major one among cutter failure modes, which is determined by the amount of cutter wear. To estimate cutter's vulnerability to wear, disc cutter wear rate is used. Based on CSM model shown in (4), disc cutter wear rate can be calculated by [20]

$$
\frac{\mathrm{d} Q}{\mathrm{~d} t}=\frac{k C T R \varphi}{H_{c}} \sqrt[3]{\frac{\sigma_{c}^{2} \sigma_{t} S}{\varphi \sqrt{R T}}} \int_{0}^{\varphi}\left(1-\frac{\phi}{\varphi}\right)^{\psi} v \mathrm{~d} \phi
$$

with

$$
\begin{aligned}
v & =\sqrt{v_{1}^{2}+v_{2}^{2}} \\
v_{1} & =2 \Omega_{0} R_{i} \sin ^{2}\left(\frac{\phi}{2}\right)+\left(\frac{\Omega_{0} p}{2 \pi}+v_{z}\right) \sin \phi-v_{t} \cos \phi \\
v_{2} & =\Omega_{0} R \sin \phi-v_{R},
\end{aligned}
$$

where $Q$ is the amount of cutter wear, $\psi$ is a constant of typically 0.2 to -0.2 for disc cutter, $\phi$ is the central angle of the arc length between a point on cutter-rock contact area and the point determining the cutter penetration as is shown in Figure 3, $k$ is wear coefficient usually of $10^{-1}$ to $10^{-6}$, $H_{c}$ is surface hardness of cutter, $\Omega_{0}$ is cutterhead rotation speed, and $v_{z}, v_{R}$, and $v_{t}$ are the perturbations of the steady velocity of cutter center in tunneling direction and radial and tangential direction on tunnel face, that is, the vibration velocity of cutter center, respectively [20]. When $v_{z}, v_{R}$, and $v_{t}$ are equal to zero, (13) is identical to the one in [19] which has no consideration of the influence of TBM vibration.

3.4. Load Sharing Coefficient. The rotation of cutterhead of TBM is driven by multiple pinions-gear ring meshing. Small difference between meshing forces $F_{p i}(i=1, \ldots, N)$ means good load transmission performance of cutterhead driving system. The load transmission performance can be evaluated by load sharing coefficient which directly reflects the load uneven level in each pinion at a certain time [22]. The load sharing coefficient of the cutterhead driving system in one tooth frequency cycle is calculated as

$$
d_{p i}=\frac{N\left(F_{p i}\right)_{\max }}{\sum_{i=1}^{N}\left(F_{p i}\right)_{\max }} .
$$


TABLE 1: Structural parameters in TBM dynamic model.

\begin{tabular}{lc}
\hline \multicolumn{1}{c}{ Structural parameters } \\
\hline Mass of TBM $(\mathrm{t})$ & 135 \\
Diameter of cutterhead $(\mathrm{m})$ & 4 \\
Length of main machine $(\mathrm{m})$ & 10 \\
Number of pinions & 8 \\
Number of cutters & 24 \\
Cutter spacing (mm) & 84 \\
Diameter of cutter $(\mathrm{mm})$ & 432 \\
Cutter tip width $(\mathrm{mm})$ & 9.2 \\
\hline
\end{tabular}

TABLE 2: Parameters of three types of rock.

\begin{tabular}{lccc}
\hline Rock type & Soft rock & Moderately hard rock & Hard rock \\
\hline Young's modulus $(\mathrm{GPa})$ & 18 & 50 & 80 \\
UCS $(\mathrm{MPa})$ & 60 & 100 & 150 \\
BTS $(\mathrm{MPa})$ & 4 & 5 & 6 \\
\hline
\end{tabular}

And the load sharing coefficient of the cutterhead driving system in one system period is calculated as

$$
D_{p}=\left|d_{p i}-1\right|_{\max }+1, \quad i=1, \ldots, N,
$$

where $d_{p i}$ is the load sharing coefficient of cutterhead driving system in one tooth frequency cycle, and $D_{p}$ is the load sharing coefficient of cutterhead driving system in one system period.

\section{Results of Performance Evaluation and Discussion}

4.1. Parameters in Numerical Simulation. The opening hard rock TBM used in an actual water tunnel project was taken as the application example in the evaluation of TBM performance. Structural parameters of the dynamic model of the opening hard rock TBM in numerical simulation are presented in Table 1. Other structural parameters in this simulation are listed in Appendix. For the main substructures mentioned in Section 2, the elastic modes are obtained by means of commercial finite element code ANSYS, resulting in a TBM dynamic model with a total of 137 generalized DOFs. Based on the rigid body modes, elastic modes, natural frequencies, mass matrices, and stiffness matrices extracted from ANSYS, entire dynamic equations (2) are constructed in MATLAB. Then the dynamic equations are solved by using MATLAB R2013a built-in function "ode45" with "RelTol" value of $1 \times 10^{-6}$ and other parameters default. The rock conditions encountered in tunneling are complicated in terms of rock property. For simplicity but not loss of generality, three types of rock, namely, soft, moderately hard, and hard rock, respectively, are considered in numerical simulation. The average values of the relevant property of the three types of rock are listed in Table 2. The operational parameters in TBM tunneling include cutterhead rotation speed $\Omega_{0}$ and advance rate $V_{0}$, by which the penetration can be determined. With different operational and rock conditions, the performance of TBM is evaluated with the four indexes introduced in Section 3.

4.2. Correlation of TBM Performance and Operational and Rock Conditions. The correlation of mean vibration energy dissipation rate $u$ and operational and rock conditions is shown in Figure 4, where the penetration changes from 4 to $12 \mathrm{~mm} / \mathrm{r}$, and the advance rate varies in the range of $0.4-0.8 \mathrm{~mm} / \mathrm{s}$. The values of operational parameters in this regime are frequently used in practical TBM tunneling projects $[1,25]$ and agree with those collected from on-site measurements shown in next subsection. It can be seen in Figure 4 that $u$ increases largely from soft rock to hard rock tunneling, with its value in the range of 900-1400, 1100-2200, and $1700-3500 \mathrm{~J} / \mathrm{s}$, respectively, which means TBM vibration becomes much stronger in hard rock tunneling. In soft rock and moderately hard rock tunneling, the variations of $u$ with varying penetration and advance rate are very complicated. In the case of hard rock tunneling, however, $u$ increases rapidly with the increase of the penetration.

The correlation of DSE and operational and rock conditions is shown in Figure 5, where maximum DSE is used as an indicator of excavation energy efficiency of TBM. It can be seen in Figure 5 that DSE increases significantly as the rock type changes from soft to hard. DSE in hard rock tunneling reaches several times as that in soft rock tunneling. For the same rock to be cut, DSE decreases and the decreasing rate becomes slow with the increase of the penetration, which is similar in trend to those simulation results presented in $[14,16]$. Furthermore, the change of DSE originates from the fact that the difference of advance rate for the same penetration is significant. For the penetration of $8 \mathrm{~mm} / \mathrm{r}$ in both soft rock and hard rock tunneling, the difference of DSE values at advance rate of 0.4 and $0.8 \mathrm{~mm} / \mathrm{s}$ is larger than $5 \%$. However, the variation of DSE with different advance rate is very complicated.

The complicated variation of DSE with different advance rate results from the influence of TBM vibration on DSE. The results of DSE in soft rock tunneling for cutterhead rotation speed of $6 \mathrm{rpm}$ and advance rate of $1.2 \mathrm{~mm} / \mathrm{s}$ are shown in Figure 6, where the results of SE are also shown for the comparison with DSE. It can be seen in Figure 6 that at strong vibration moments DSE increases significantly with the appearance of multiple peaks on the curve of DSE, leading to the decrease of excavation energy efficiency. When TBM vibrates weakly, DSE decreases to a value close to SE which takes no consideration of the influence of vibration. The slight variation of SE with time is due to variation of excavated rock volume which is influenced by dynamic cutter penetration.

The statistical results, that is, the mean and the standard deviation of percentage increases of maximum DSE and mean DSE relative to SE, are shown in Figure 7. It is seen that the percentage increase of maximum DSE to SE is nearly $8 \%$ and that of mean DSE to SE is about $1.4 \%$. In other words, the ratio of vibration energy dissipation to the energy consumed in rock breakage is approximately $1.4 \%$ in the whole TBM tunneling process but can reach as high as $8 \%$ at the strongest vibration moment. The fluctuation of the 

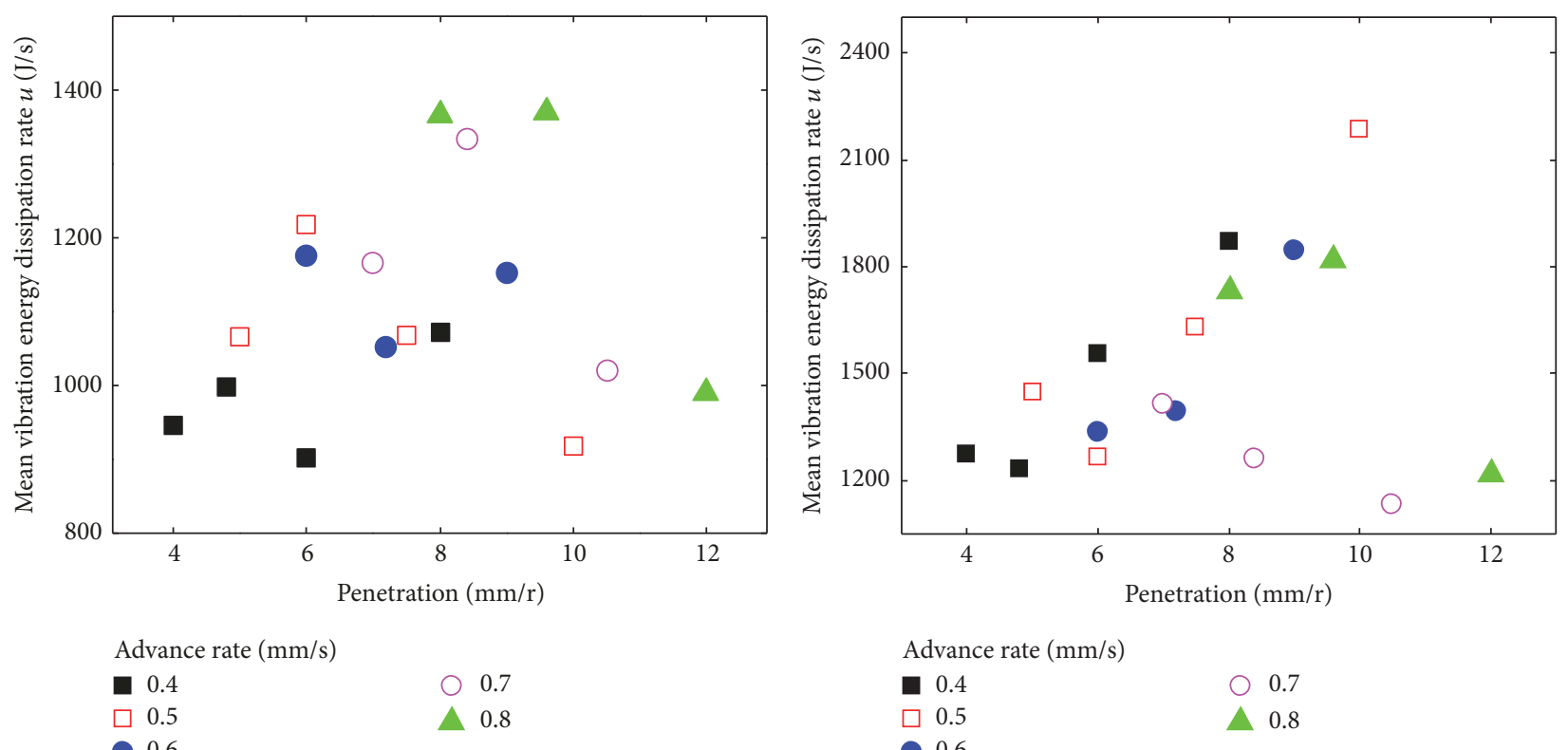

Advance rate $(\mathrm{mm} / \mathrm{s})$

\begin{tabular}{|c|c|}
\hline 0.4 & $\bigcirc \quad 0.7$ \\
\hline 0.5 & $\begin{array}{r}-1 \\
\end{array}$ \\
\hline
\end{tabular}

(a)

(b)

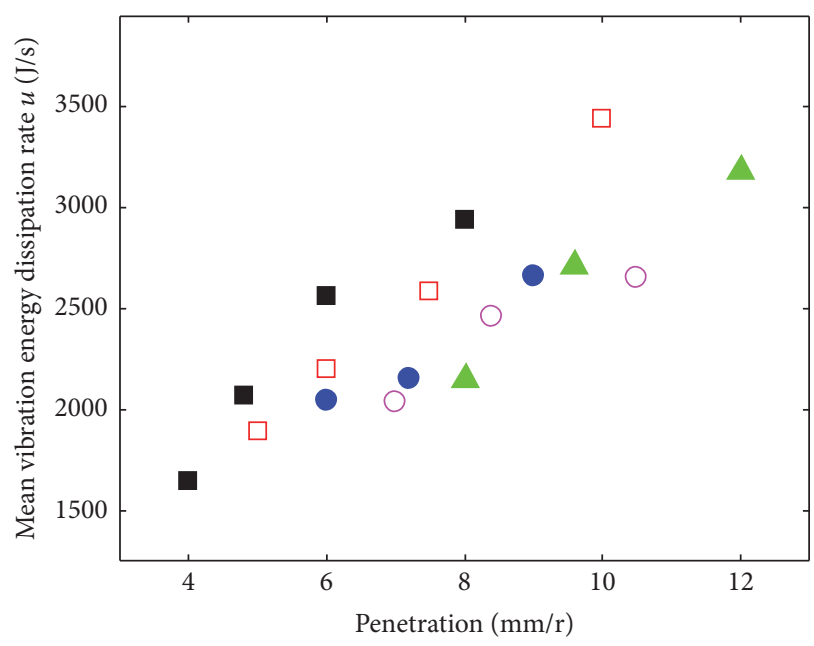

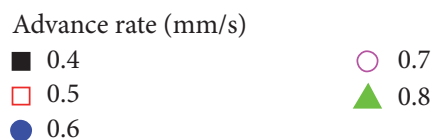

(c)

FIGURE 4: Correlation of mean vibration energy dissipation rate $u$ and operational parameters for (a) soft rock, (b) moderately hard rock, and (c) hard rock.

results in hard rock tunneling is larger than those in soft and medium hard rock tunneling, which results from the stronger impact of TBM vibration in hard rock tunneling. It can be concluded that severe vibration in TBM largely deteriorates the excavation energy efficiency. In addition, the fluctuation of maximum DSE shown is larger than that of mean DSE, which means maximum DSE is more effective and sensitive in revealing the variation of DSE with operational and rock conditions.

The change of mean cutter wear rate with the operational and rock conditions is shown in Figure 8, where wear rate is for the cutter mounted on cutterhead panel at a radius of $1 \mathrm{~m}$. As shown in the figure, for the same rock to be cut, cutter wear rate increases with the increase of the penetration, which is in accordance with the results presented in [19]. Furthermore, the increase of cutter wear rate with the change of rock type from soft to hard indicates that the cutter is more vulnerable to wear and the prematurity of cutter failure caused by wear more easily occurring in hard rock tunneling than in soft rock tunneling, which agrees with project practice [1]. With the type of rock and penetration held constant, the cutter wear rate increases with the increase of the advance rate. This is 

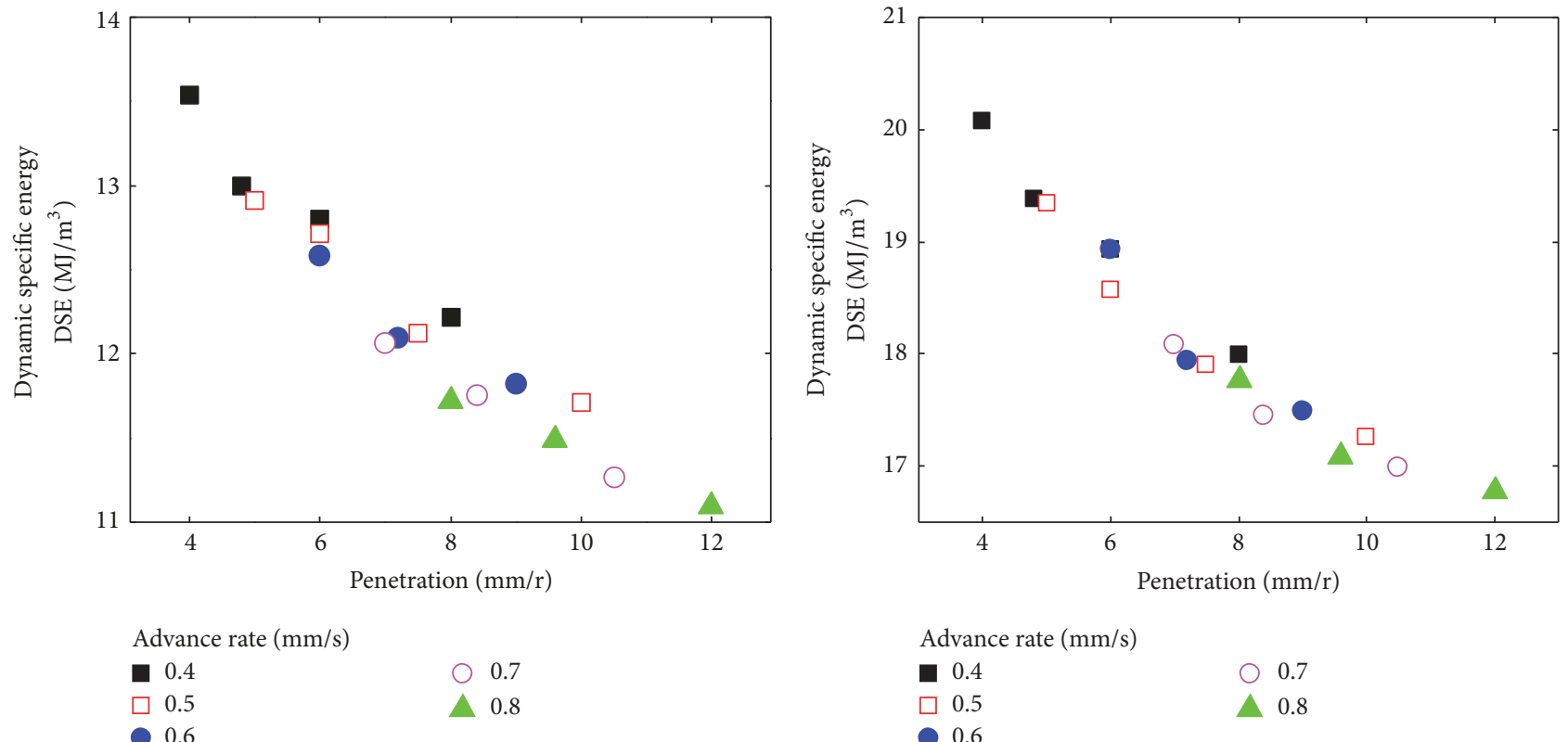

\begin{tabular}{|c|c|}
\hline Advan & \\
\hline 口 0.4 & $\bigcirc 0.7$ \\
\hline$\square 0.5$ & $\triangle 0.8$ \\
\hline
\end{tabular}

(a)

(b)

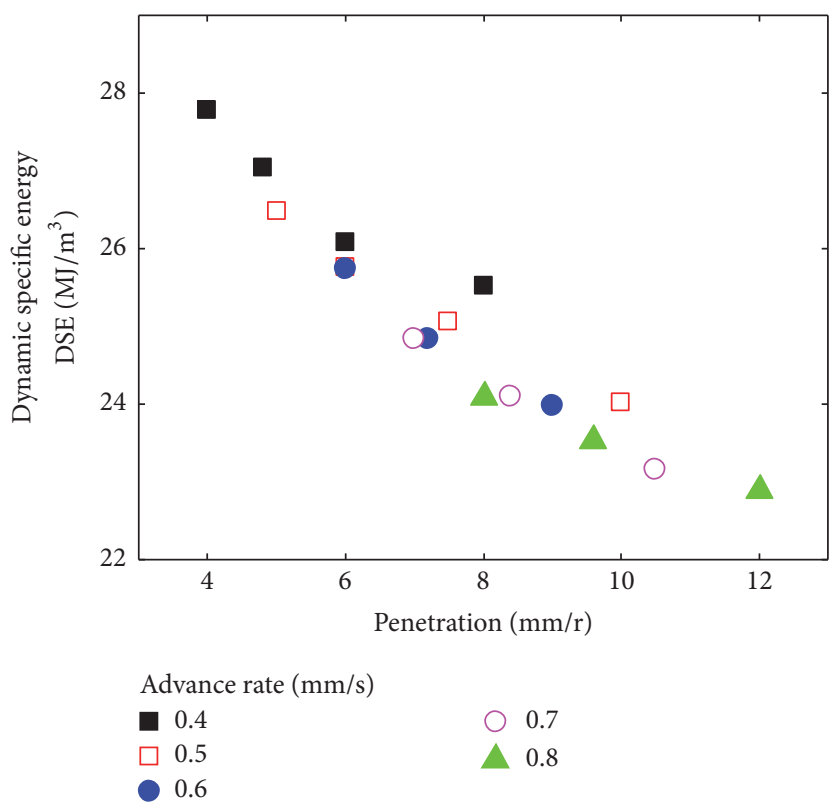

(c)

FIGURE 5: Correlation of dynamic specific energy (DSE) and operational parameters for (a) soft rock, (b) moderately hard rock, and (c) hard rock.

because higher advance rate results in larger excavated rock volume in a unit time and consequently increases the amount of cutter wear in a unit time.

The time history of wear rate of this cutter is shown in Figure 9, where the mean wear rate and the wear rate without considering vibration are also shown. As is illustrated, the cutter wear rate oscillates strongly with time, and its peaks are several times of the wear rate without considering vibration. Comparing with the wear rate without considering vibration, the mean wear rate of the cutter at a radius of
$1 \mathrm{~m}$ increases by $7.5 \%$ in this case. Therefore, affected by vibration, cutters are more vulnerable to wear than without vibration.

The statistical results, that is, the mean and the standard deviation of percentage increases of mean wear rate compared with the wear rate without considering vibration for this cutter, are shown in Figure 10. It is shown that the percentage increase of mean wear rate of cutter caused by TBM vibration reaches $8 \%, 10 \%$, and $18 \%$ in soft rock, moderately hard rock, and hard rock tunneling, respectively. 


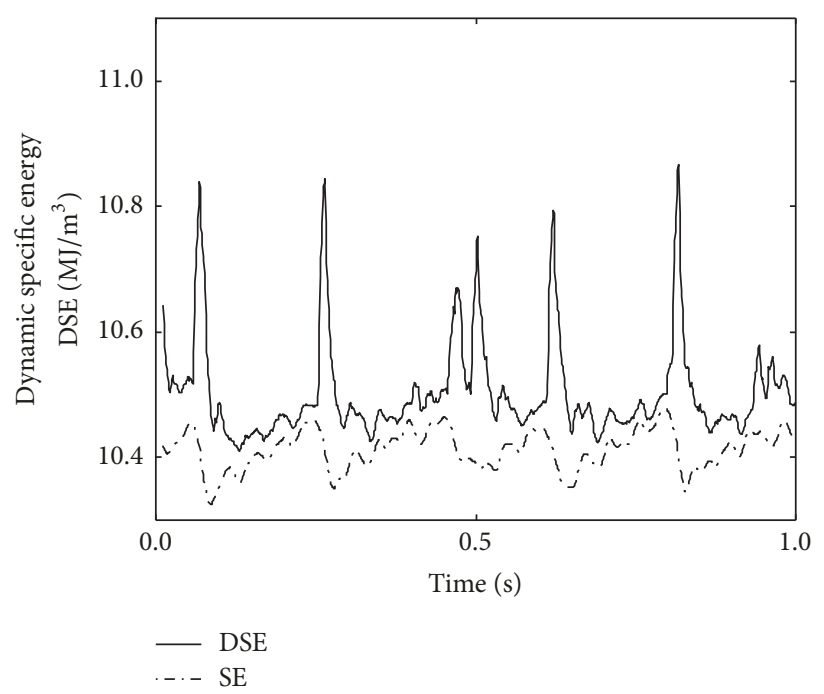

FIGURE 6: DSE in soft rock tunneling for $\Omega_{0}=6 \mathrm{rpm}$ and $V_{0}=1.2 \mathrm{~mm} / \mathrm{s}$.

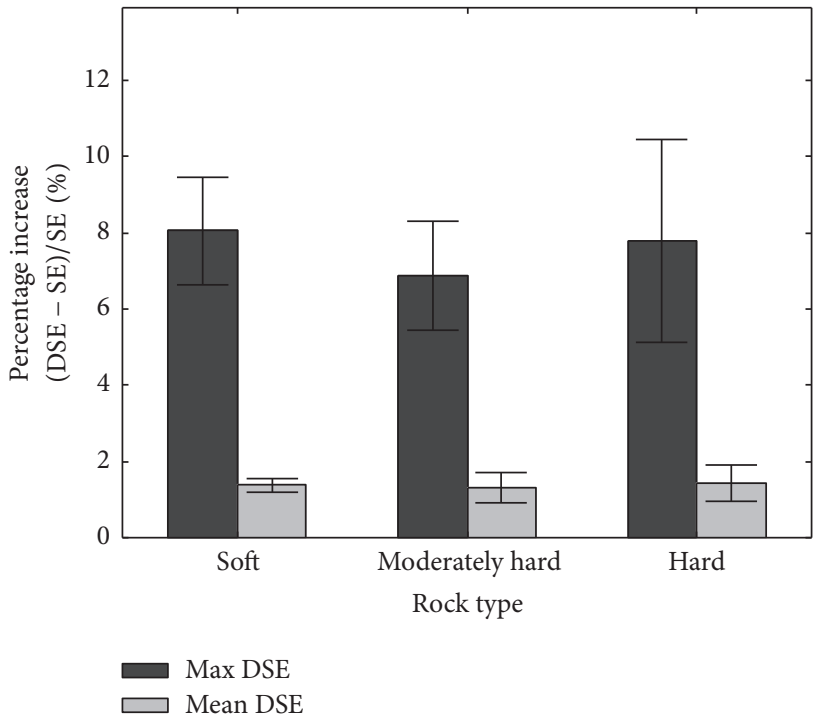

FIgURE 7: Percentage increases of maximum DSE and mean of DSE relative to SE.

The fluctuation of the results in hard rock tunneling is larger than those in soft and moderately hard rock tunneling. Also it is revealed that the TBM in high vibration level for hard rock tunneling worsens the working condition of disc cutter and accelerates cutter wear. Therefore, excessive vibration should be avoided as far as possible to protect cutters from wear too fast.

The correlation of load sharing coefficient of the cutterhead driving system and operational and rock conditions is shown in Figure 11. It can be seen that the correlation of load sharing coefficient and operational parameters, that is, penetration and advance rate, is very complicated. Overall the load sharing coefficient varies between 1.35 and 1.65 when operational parameters change in the regime of advance rate of $0.4-0.8 \mathrm{~mm} / \mathrm{s}$ and penetration of $4-12 \mathrm{~mm} / \mathrm{r}$, and it also slightly decreases with the change of rock type from soft to hard. From (4) it can be seen that with other parameters held constant cutter forces increase when the rock to be cut becomes harder, which leads to a larger driving torque in cutterhead driving system. Therefore, the results of the slight decrease of load sharing coefficient with the change of rock type from soft to hard are in accordance with the conclusion that load sharing seems to get better for higher torque [27]. Although load transmission performance slightly changes with different rock types, higher torque in harder rock tunneling increases the absolute difference between meshing forces loaded on pinions and more easily causes structure damage such as tooth fracture and shaft broken of pinions.

4.3. Results of Vibration and DSE from On-Site Measurement and Tunneling Data Collection. An on-site measurement of TBM vibration acceleration was performed for the opening hard rock TBM used in an actual water tunnel project. The 


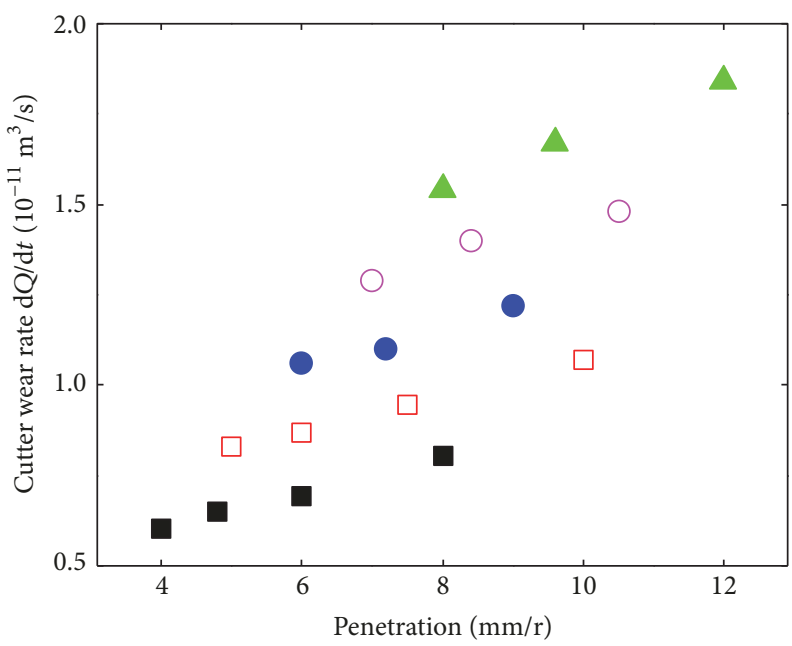

Advance rate $(\mathrm{mm} / \mathrm{s})$

\begin{tabular}{|c|c|}
\hline 0.4 & $\bigcirc \quad 0.7$ \\
\hline 0.5 & $\begin{array}{r}\Delta \quad 0.8 \\
\end{array}$ \\
\hline
\end{tabular}

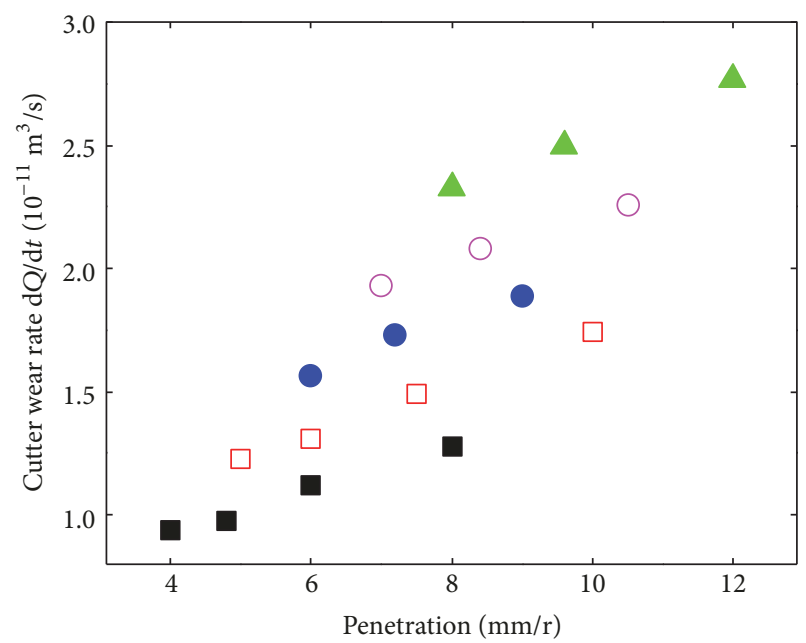

Advance rate $(\mathrm{mm} / \mathrm{s})$

\begin{tabular}{|c|c|}
\hline 0.4 & $\bigcirc \quad 0.7$ \\
\hline$\square 0.5$ & A $\quad 0.8$ \\
\hline
\end{tabular}

(b)

0.6

(a)

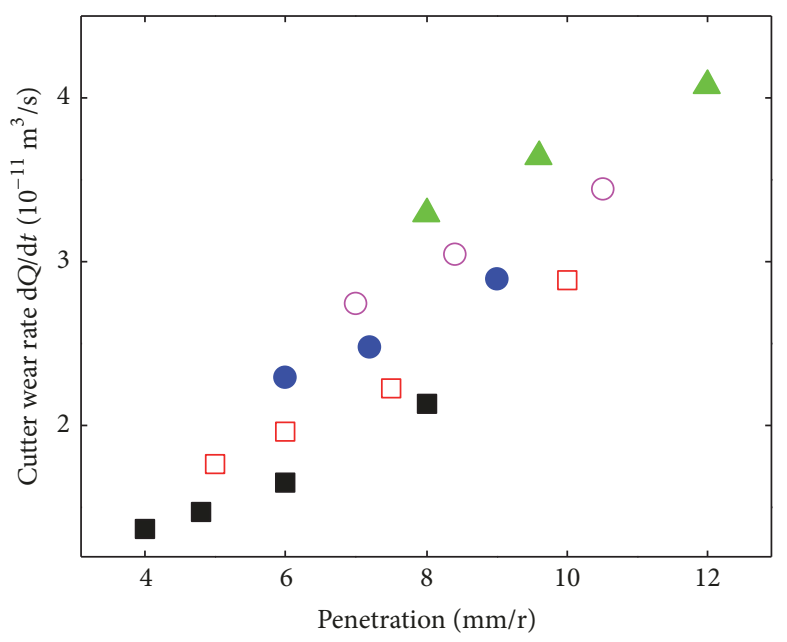

Advance rate $(\mathrm{mm} / \mathrm{s})$

\begin{tabular}{|c|c|}
\hline 0.4 & $\bigcirc \quad 0.7$ \\
\hline$\square 0.5$ & $\triangle 0.8$ \\
\hline
\end{tabular}

(c)

FIGURE 8: Correlation of cutter wear rate and operational parameters for (a) soft rock, (b) moderately hard rock, and (c) hard rock.

vibration measurement system consists of a data acquisition system, a laptop, several 3-directional accelerometers, and connecting wires. The time history of acceleration was then acquired during TBM tunneling. The measuring points in this on-site measurement were distributed on main beam and grippers. Figure 12 shows two measuring points at main beam back tip and right gripper, respectively. A sample frequency of $1000 \mathrm{~Hz}$ was adopted in this TBM vibration measurement.

The water tunnel project where the on-site measurement is carried out is in Northeast, China, and is a part of Liaoning Northwest Water Supply Project. The tunneling section at measurement moment is buried at depth of $200 \mathrm{~m}$ and is located in a geological fault zone, where the major constituent of rock mass is granodiorite. Rock mass is not very stable in the developed joint fissures zone, with a wide range of rock blocks falling from tunnel arch and water gushing. According to the project office, the rock mass encountered in the measurement section is classified as soft rock or moderately hard rock.

The results of acceleration response at main beam back tip and right gripper obtained by numerical simulation are compared with those obtained from on-site acceleration measurement. For example, Figure 13 shows the comparison 


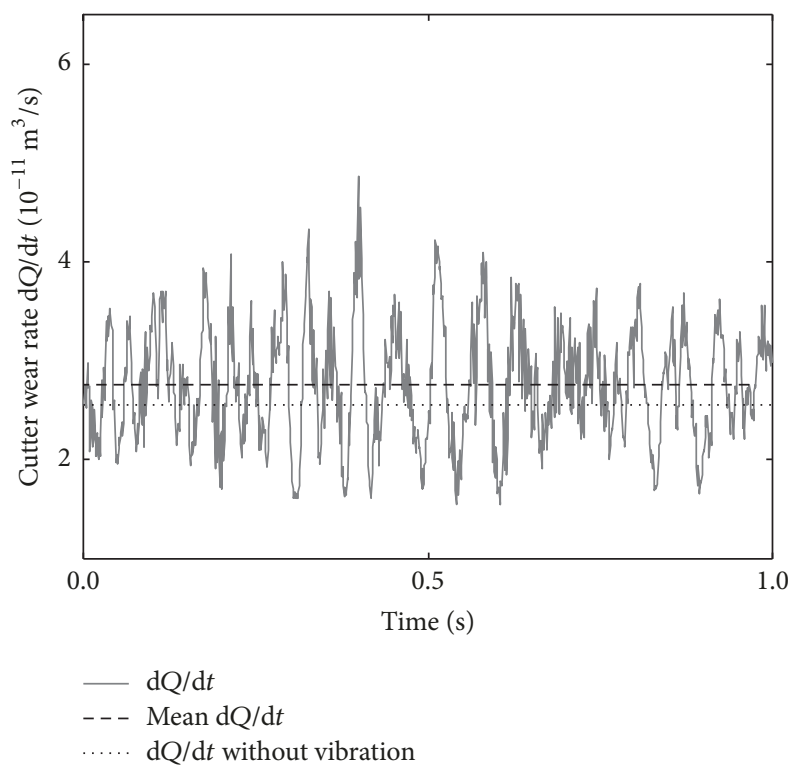

FigURE 9: Cutter wear rate in soft rock tunneling for $\Omega_{0}=6 \mathrm{rpm}$ and $V_{0}=1.2 \mathrm{~mm} / \mathrm{s}$.

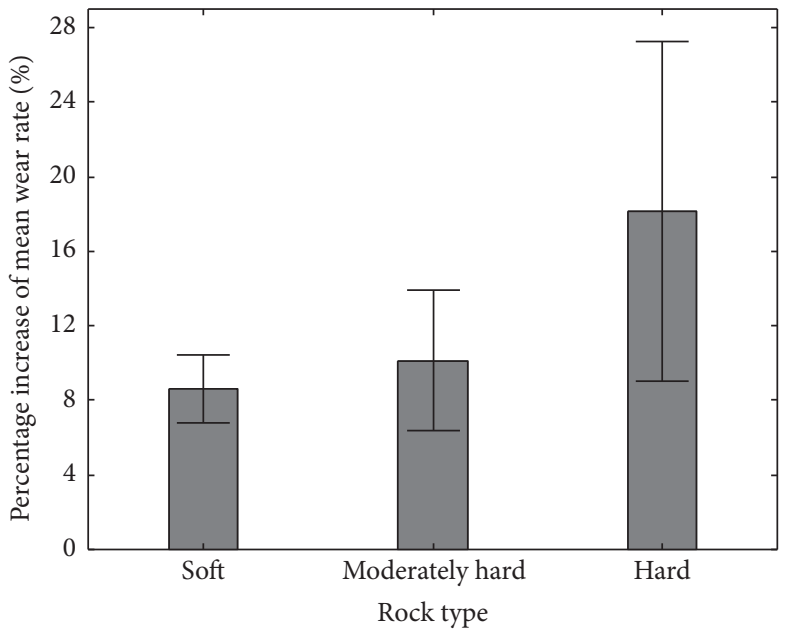

Figure 10: Percentage increases of mean cutter wear rate caused by vibration.

of acceleration responses at main beam back tip in $X$ direction, where the parameters cutterhead rotation speed of $6 \mathrm{rpm}$, advance rate of $1.2 \mathrm{~mm} / \mathrm{s}$, and soft rock in simulation are close to those in measurement. The values of acceleration time history between simulation and measurement results are quite close, and the distribution of dominant spectrum peaks in frequency spectrum between simulation and measurement results is similar. The reasonable agreement between simulated acceleration and measured acceleration shows that the developed dynamic model of TBM is reasonably faithful.

The correlation of TBM vibration level and operational parameters obtained from this on-site measurement and tunneling data collection is revealed by Figure 14, where the TBM vibration level is simply evaluated by the RMS of acceleration in $Z$-direction measured at main beam back tip. The correlation of DSE and operational parameters obtained is shown in Figure 15, where the dashed red line denotes the quadratic fitting line of the scattered data shown in Figure 5(a). Geological conditions of fault zone encountered in this on-site measurement are very complicated and lead to large margin variations of acceleration RMS and DSE as shown in Figures 14 and 15, respectively. Operational parameters, that is, the penetration and advance rate, also exert significant influence on these results. In tendency, the correlation of vibration level and operational parameters obtained from on-site measurement revealed by Figure 14 is similar to the obtained simulation results in Figure 4(a), and the correlation of DSE and operational parameters obtained from on-site measurement in Figure 15 is similar to the obtained simulation results. The reasonable trend agreement between the simulation correlations of vibration level and DSE with operational parameters and those obtained from on-site measurement in soft rock tunneling validates 

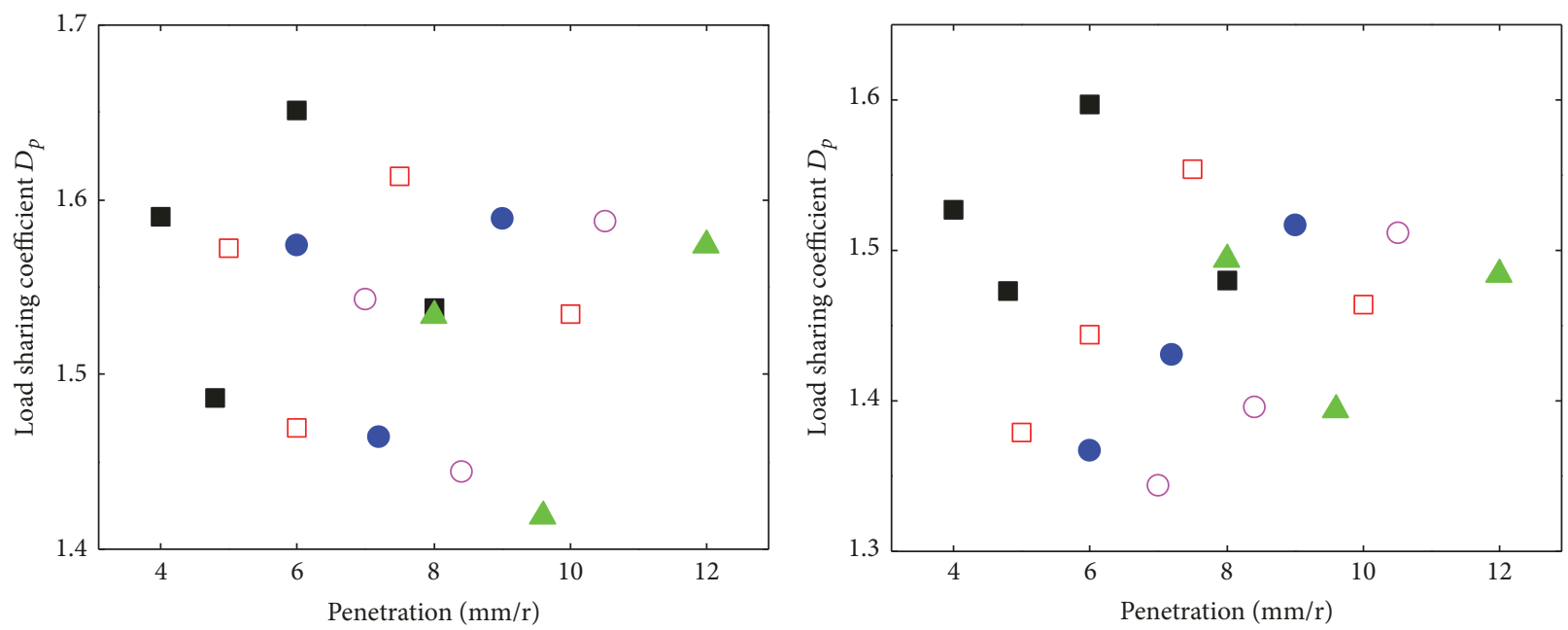

$\begin{array}{ll}\text { Advance rate }(\mathrm{mm} / \mathrm{s}) & \\ 0.4 & \bigcirc 0.7 \\ 0.5 & -0.8\end{array}$

\begin{tabular}{|c|c|}
\hline Advanc & \\
\hline 口 0.4 & $\bigcirc 0.7$ \\
\hline$\square 0.5$ & $\Delta 0$ \\
\hline
\end{tabular}

(a)

(b)

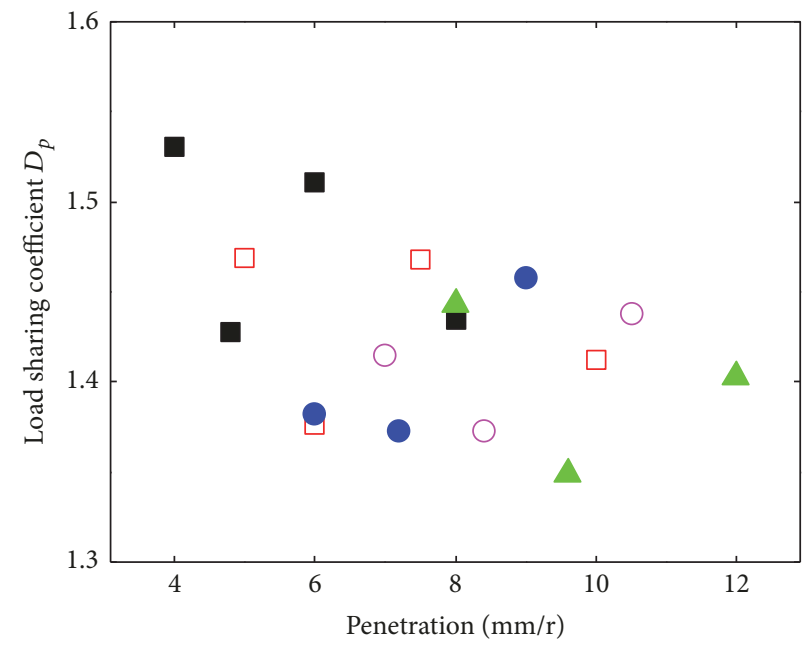

$\begin{array}{ll}\text { Advance rate }(\mathrm{mm} / \mathrm{s}) & \\ \square 0.4 & \bigcirc 0.7 \\ \square 0.5 & \triangle 0.8 \\ 0.6 & \end{array}$

(c)

FIGURE 11: Correlation of load sharing coefficient and operational parameters for (a) soft rock, (b) moderately hard rock, and (c) hard rock.

the performance evaluation of hard rock TBMs presented in this paper.

\section{Conclusions}

From the investigations of TBM performance considering operational and rock conditions, three major concluding remarks can be made as follows.

(1) The values of mean vibration energy dissipation rate $u$, DSE, and cutter wear rate increase significantly when the type of rock to be cut changes from soft to hard with operational parameters held constant. However, the variations of these performance indexes with the change of operational parameters are with different tendency from each other. For the cases of soft rock and moderately hard rock tunneling, the variation of $u$ is very complex with changing penetration and advance rate. For the case of hard rock tunneling, generally $u$ significantly increases with the increased penetration. DSE decreases with the increase of penetration and varies significantly with the change of advance rate. Cutter wear rate increases significantly with both the increased penetration and advance rate. For the correlation of load sharing coefficient and operational and 


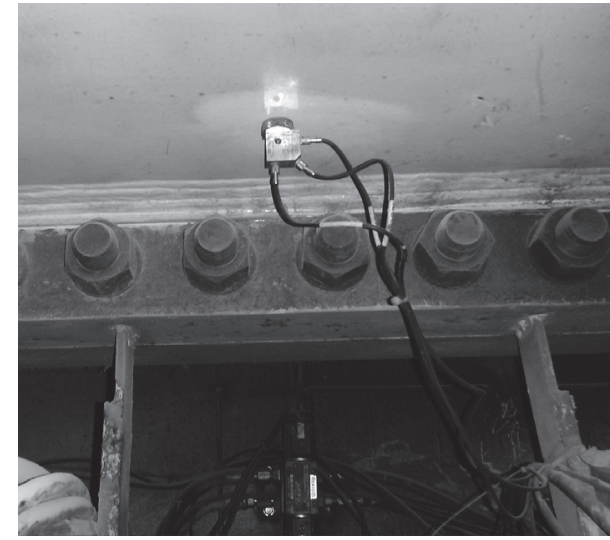

(a)

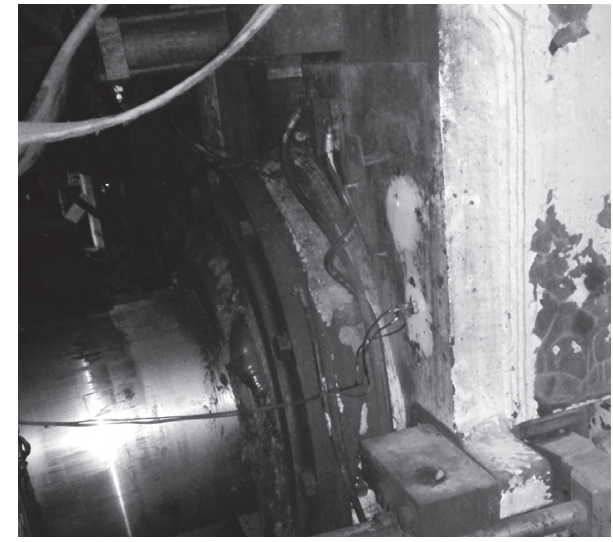

(b)

FIGURE 12: Measuring point at (a) main beam back tip and (b) right gripper.

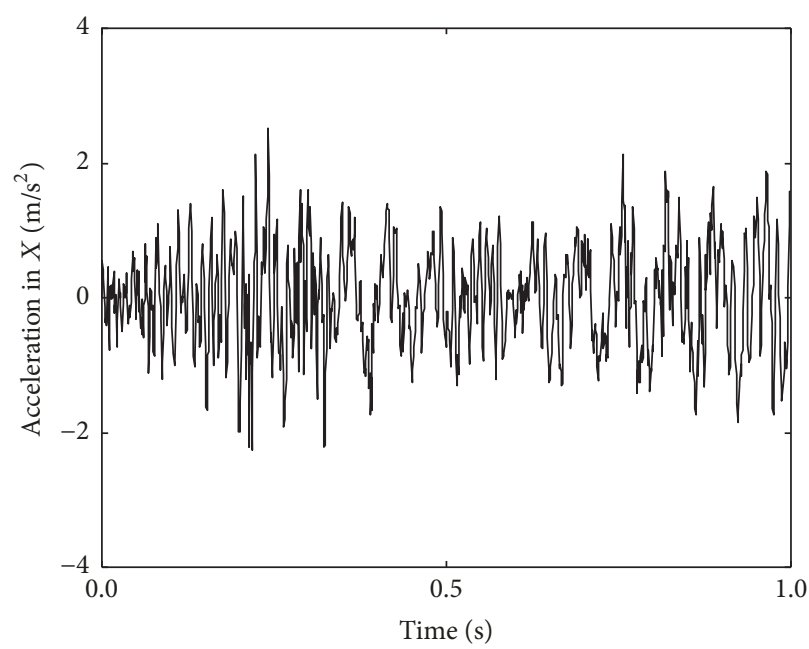

(a)

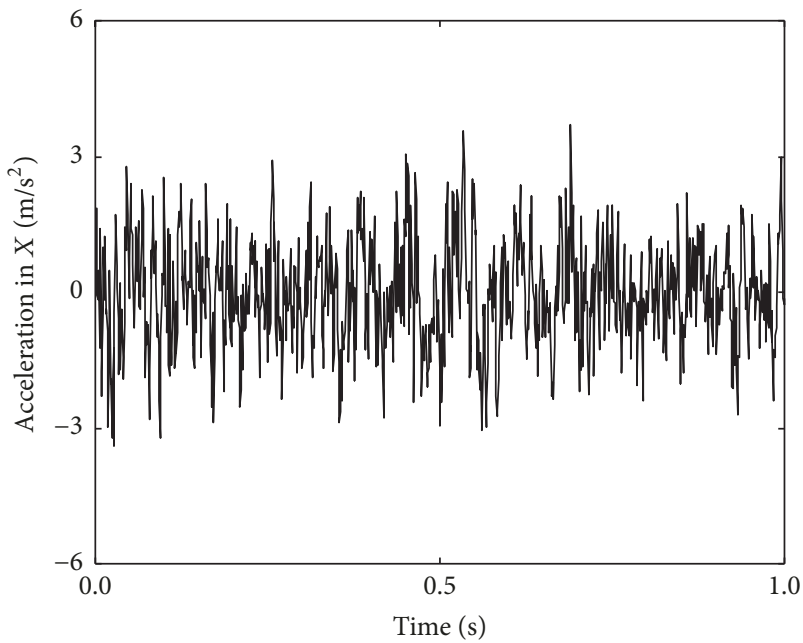

(c)

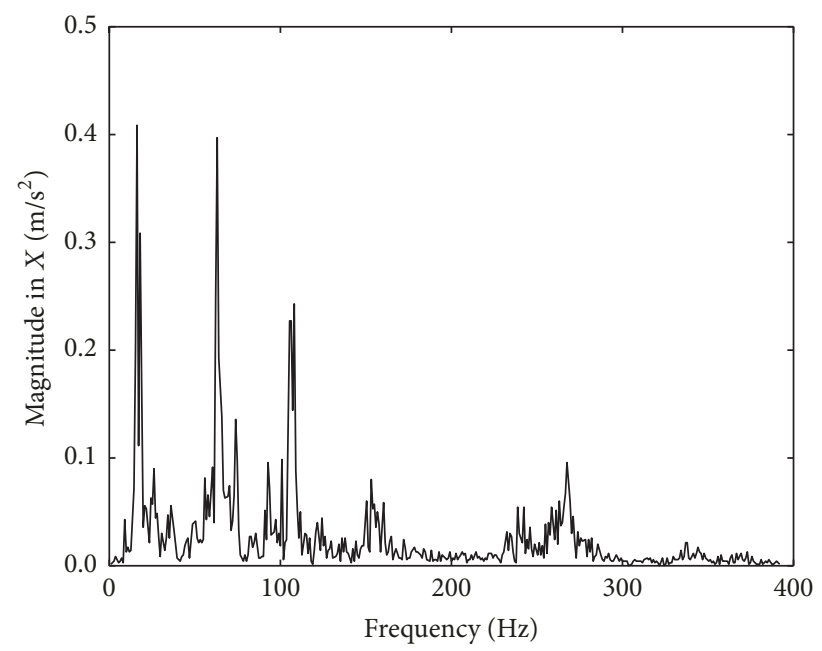

(b)

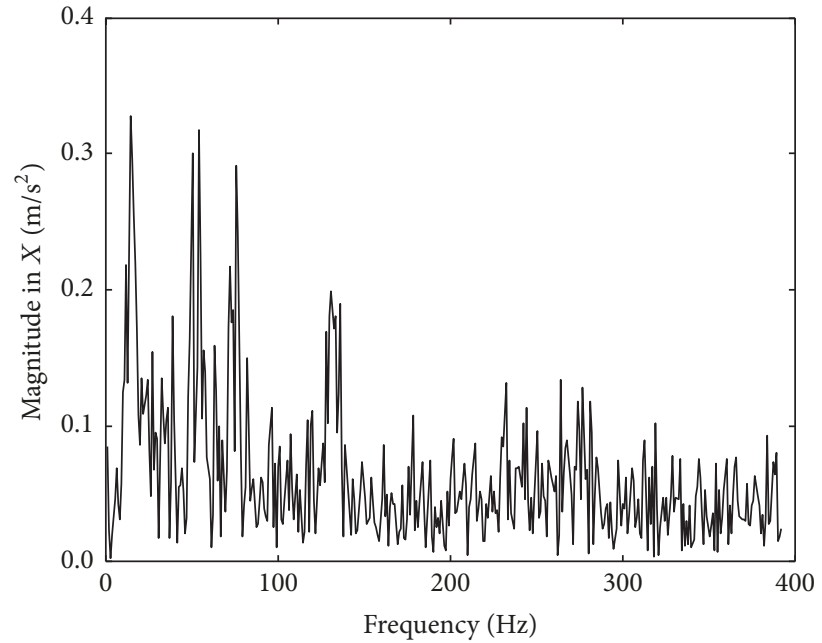

(d)

FIGURE 13: Acceleration responses of (a) simulated time history, (b) simulated spectrum, (c) measured time history, and (d) measured spectrum at main beam back tip in $X$-direction. 


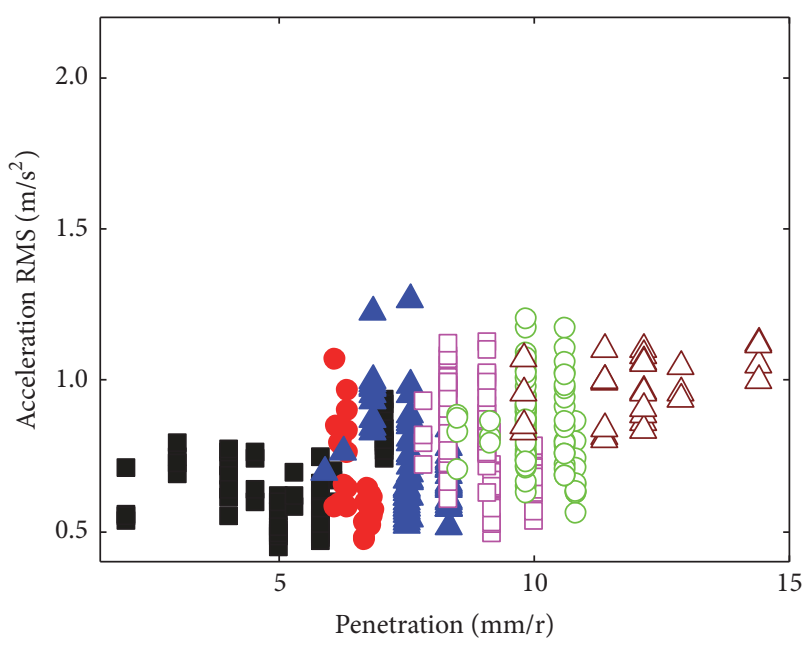

Advance rate $(\mathrm{mm} / \mathrm{s})$
$\square<0.4$
$\square 0.6-0.7$
$0.4-0.5$
$0.7-0.8$
0.5-0.6
$\triangle>0.8$

FIGURE 14: Correlation of acceleration RMS in Z-direction measured at main beam back tip and operational parameters.

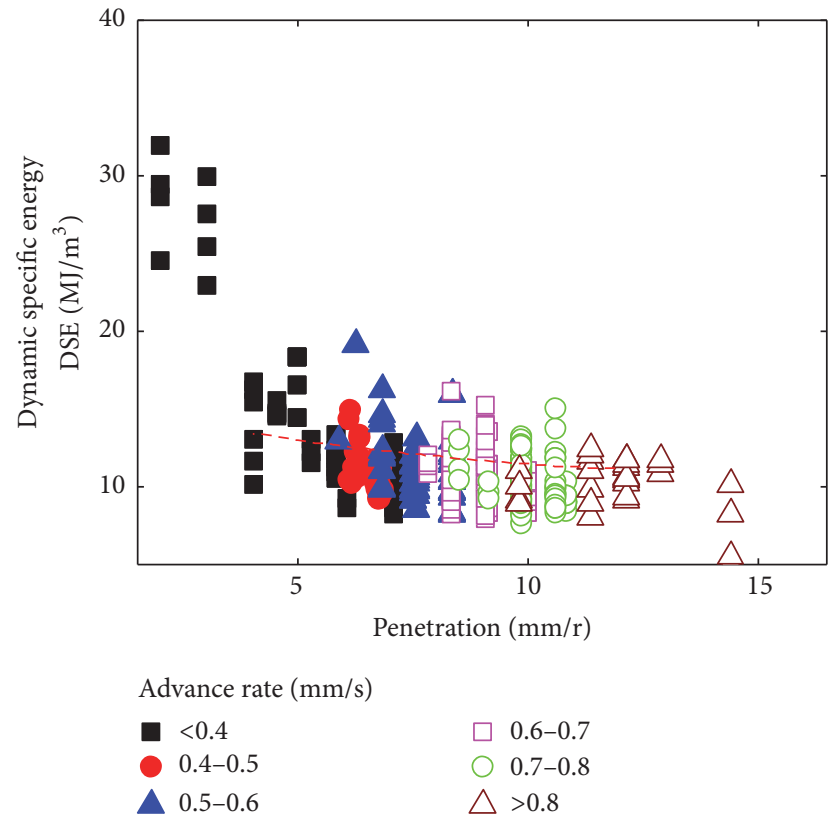

FIGURE 15: Correlation of DSE and operational parameters obtained from on-site measurement (dashed red line is the fitted curve of simulation DSE in soft rock tunneling).

rock conditions, the overall trend is that changing operational parameters results in a large margin variation of load sharing coefficient and the change of rock type from soft to hard makes the load sharing coefficient decrease slightly.

(2) Due to the TBM's severe vibration, DSE and cutter wear rate oscillate strongly with time. In the regime of advance rate of $0.4-0.8 \mathrm{~mm} / \mathrm{s}$ and penetration of $4-12 \mathrm{~mm} / \mathrm{r}$, statistically the percentage increase of DSE to specific energy (SE) is nearly $8 \%$ at the strongest vibration moment, which means vibration significantly deteriorates the excavation energy efficiency of a TBM. The percentage increases of mean wear rate of cutter caused by TBM vibration reaches $8 \%, 10 \%$, and $18 \%$ in soft rock, moderately hard rock, and hard rock tunneling, respectively, which means that TBM vibration worsens the working condition of disc cutter and accelerates cutter wear, especially in hard rock tunneling.

(3) The simulation results are basically consistent with the field measurements. These results could provide the foundation for a more comprehensive evaluation of TBM performance in actual tunneling process.

\section{Appendix}

Structural parameters in this simulation are as follows:

$$
\begin{aligned}
& M_{1}=45.8 \mathrm{t} ; \\
& M_{2}=16.2 \mathrm{t} ; \\
& M_{3}=3.8 \mathrm{t} ; \\
& M_{4}=3.7 \mathrm{t} ; \\
& M_{5}=2.0 \mathrm{t} ; \\
& M_{6}=2.0 \mathrm{t} ; \\
& M_{7}=27.8 \mathrm{t} ; \\
& M_{8}=14.1 \mathrm{t} ; \\
& M_{9}=6.3 \mathrm{t} ; \\
& M_{10}=1.5 \mathrm{t} ; \\
& M_{11}=1.5 \mathrm{t} ; \\
& M_{12}=5.1 \mathrm{t} ; \\
& M_{13}=5.1 \mathrm{t} ; \\
& m_{p i}=0.1 \mathrm{t} ; \\
& I_{p i}=1 \times 10^{6} \mathrm{tmm}^{2} ; \\
& b_{p i}=0.02 \mathrm{~mm} ; \\
& k_{p i}=1 \times 10^{6} \mathrm{Nmm}^{-1} ; \\
& k_{m i}=1 \times 10^{6} \mathrm{Nmm}^{-1} ; \\
& k_{b 1 i}, k_{b 2 i}, k_{b 3 i}=1 \times 10^{6} \mathrm{Nmm}^{-1} ; \\
& k_{b s x i}, k_{b s z i}=4 \times 10^{6} \mathrm{Nmm}^{-1} ; \\
& k_{b s y i}=8 \times 10^{6} \mathrm{Nmm}^{-1} ; \\
& k_{g b x i}, k_{g b y i}=1 \times 10^{6} \mathrm{Nmm}^{-1} ;
\end{aligned}
$$




$$
\begin{aligned}
& k_{g b z i}=2 \times 10^{6} \mathrm{Nmm}^{-1} ; \\
& k_{t s x 1}, k_{t s x 2}, k_{t s z 1}, k_{t s z 2}=5 \times 10^{6} \mathrm{Nmm}^{-1} ; \\
& k_{t s z 1}, k_{t s z 2}=5 \times 10^{4} \mathrm{Nmm}^{-1} ; \\
& k_{s h i 1}, k_{s h i 2}=5 \times 10^{4} \mathrm{Nmm}^{-1} ; \\
& k_{l s x}, k_{r s x}=5 \times 10^{6} \mathrm{Nmm}^{-1} ; \\
& k_{b l}, k_{b r}, k_{t l}, k_{t r}=1 \times 10^{7} \mathrm{Nmm}^{-1} ; \\
& k_{g x 1}, k_{g x 2}, k_{g y 1}, k_{g y 2}=1 \times 10^{7} \mathrm{Nmm}^{-1} ; \\
& k_{t h t 1}, k_{t h t 2}, k_{t h t 3}, k_{t h t 4}=2.4 \times 10^{5} \mathrm{Nmm}^{-1} ; \\
& k_{t o r 1}, k_{t o r 2}, k_{t o r 3}, k_{t o r 4}=5.5 \times 10^{5} \mathrm{Nmm}^{-1} ; \\
& k_{j x}, k_{j z}=5 \times 10^{5} \mathrm{Nmm}^{-1} ; \\
& k_{s u p x 1}, k_{s u p x 2}=1.3 \times 10^{6} \mathrm{Nmm}^{-1} ; \\
& k_{s u p y 1}, k_{s u p y 2}, k_{s u p z 1}, k_{s u p z 2}=1 \times 10^{7} \mathrm{Nmm}^{-1} ; \\
& k_{s j x 1}, k_{s j x 2}, k_{s j y 1}, k_{s j y 2}, k_{s j z 1}, k_{s j z 2}=5 \times 10^{7} \mathrm{Nmm}^{-1} .
\end{aligned}
$$

The equivalent damping coefficients can be obtained by using damping ratios as recommended in [10].

\section{Conflicts of Interest}

The authors declare no conflicts of interest, including specific financial interests and relationships relevant to subject of this paper.

\section{Acknowledgments}

This work is financially supported by the Basic Research Program of China (973 Program) (Grant no. 2013CB035403).

\section{References}

[1] B. Maidl, L. Schmid, W. Rits, and M. Herrenknecht, Hardrock Tunnel Boring Machines, Ernst and Sohn, Berlin, Germany, 2008.

[2] A. E. Samuel and L. P. Seow, "Disc force measurements on a full-face tunneling machine," International Journal of Rock Mechanics and Mining Sciences and Geomechanics Abstracts, vol. 21, no. 2, pp. 83-96, 1984.

[3] Z. X. Zhang, S. Q. Kou, X. C. Tan, and P.-A. Lindqvist, "Insitu measurements of cutter forces on boring machine at Äspö Hard Rock Laboratory. Part I. Laboratory calibration and insitu measurements," Rock Mechanics and Rock Engineering, vol. 36, no. 1, pp. 39-61, 2003.

[4] Z. X. Zhang, S. Q. Kou, and P.-A. Lindqvist, "In-situ measurements of cutter forces on boring machine at Äspö Hard Rock Laboratory. Part II. Characteristics of cutter forces and examination of cracks generated," Rock Mechanics and Rock Engineering, vol. 36, no. 1, pp. 63-83, 2003.
[5] Z. X. Zhang, "Estimate of loading rate for a TBM machine based on measured cutter forces," Rock Mechanics and Rock Engineering, vol. 37, no. 3, pp. 239-248, 2004.

[6] M. Entacher, G. Winter, T. Bumberger, K. Decker, I. Godor, and R. Galler, "Cutter force measurement on tunnel boring machines - System design," Tunnelling and Underground Space Technology, vol. 31, pp. 97-106, 2012.

[7] M. Entacher, G. Winter, and R. Galler, "Cutter force measurement on tunnel boring machines - Implementation at Koralm tunnel," Tunnelling and Underground Space Technology, vol. 38, pp. 487-496, 2013.

[8] M. Entacher, K. Lassnig, and R. Galler, "Analysis of force path diagrams of linear cutting machine-tests regarding geotechnical parameters," in Proceedings of the GeoCongress 2012: State of the Art and Practice in Geotechnical Engineering, pp. 3258-3267, USA, March 2012.

[9] J. Huo, H. Wu, G. Li, W. Sun, and J. Chen, "The coupling dynamic analysis and field test of TBM main system under multipoint impact excitation," Shock and Vibration, vol. 2015, Article ID 313259, 14 pages, 2015.

[10] W. Sun, J. Ling, J. Huo, L. Guo, X. Zhang, and L. Deng, "Dynamic characteristics study with multidegree-of-freedom coupling in TBM cutterhead system based on complex factors," Mathematical Problems in Engineering, vol. 2013, Article ID 635809, 17 pages, 2013.

[11] X. Y. Zou, H. Zheng, Y. Z. Mi, and X. Xie, "A study on vibration of tunnel boring machine and the induced shield tangential force," Journal of Vibrational Engineering and Technologies, vol. 4, no. 4, pp. 373-381, 2016.

[12] R. Gertsch, L. Gertsch, and J. Rostami, "Disc cutting tests in Colorado Red Granite: Implications for TBM performance prediction," International Journal of Rock Mechanics and Mining Sciences, vol. 44, no. 2, pp. 238-246, 2007.

[13] J.-W. Cho, S. Jeon, S.-H. Yu, and S.-H. Chang, "Optimum spacing of TBM disc cutters: A numerical simulation using the three-dimensional dynamic fracturing method," Tunnelling and Underground Space Technology, vol. 25, no. 3, pp. 230-244, 2010.

[14] J.-W. Cho, S. Jeon, H.-Y. Jeong, and S.-H. Chang, "Evaluation of cutting efficiency during TBM disc cutter excavation within a Korean granitic rock using linear-cutting-machine testing and photogrammetric measurement," Tunnelling and Underground Space Technology, vol. 35, pp. 37-54, 2013.

[15] Z. X. Zhang, S. Q. Kou, L. G. Jiang, and P.-A. Lindqvist, "Effects of loading rate on rock fracture: fracture characteristics and energy partitioning," International Journal of Rock Mechanics and Mining Sciences, vol. 37, no. 5, pp. 745-762, 2000.

[16] L. Wang, Y. Kang, Z. Cai et al., "The energy method to predict disc cutter wear extent for hard rock TBMs," Tunnelling and Underground Space Technology, vol. 28, no. 1, pp. 183-191, 2012.

[17] H.-S. Jung, J.-M. Choi, B.-S. Chun, J.-S. Park, and Y.-J. Lee, "Causes of reduction in shield TBM performance - A case study in Seoul," Tunnelling and Underground Space Technology, vol. 26, no. 3, pp. 453-461, 2011.

[18] L. Wang, Y. Kang, X. Zhao, and Q. Zhang, "Disc cutter wear prediction for a hard rock TBM cutterhead based on energy analysis," Tunnelling and Underground Space Technology, vol. 50, pp. 324-333, 2015.

[19] Q. Tan, L. Xie, Y. Xia, Z. Zhu, X. Sun, and Y. Wang, "Analysis of wear rate of TBM disc cutter," Journal of Central South University Science and Technology, vol. 46, no. 3, pp. 843-848, 2015.

[20] X. Zou, Y. Mi, H. Zheng, and J. Tao, "Influence of vibration on the performance of tunnel boring machines," in Proceedings of 
the 12th IEEE/ASME International Conference on Mechatronic and Embedded Systems and Applications, MESA 2016, New Zealand, August 2016.

[21] H. Yu, P. Eberhard, Y. Zhao, and H. Wang, "Sharing behavior of load transmission on gear pair systems actuated by parallel arrangements of multiple pinions," Mechanism and Machine Theory, vol. 65, pp. 58-70, 2013.

[22] J. Wei, Q. Sun, W. Sun, X. Ding, W. Tu, and Q. Wang, "Loadsharing characteristic of multiple pinions driving in tunneling boring machine," Chinese Journal of Mechanical Engineering, vol. 26, no. 3, pp. 532-540, 2013.

[23] J. Hong, Computational Dynamics of Multibody System, Higher Education Press, Beijing, 1999, in Chinese.

[24] C. Germay, V. Denoël, and E. Detournay, "Multiple mode analysis of the self-excited vibrations of rotary drilling systems," Journal of Sound and Vibration, vol. 325, no. 1-2, pp. 362-381, 2009.

[25] J. Rostami, "Hard rock TBM cutterhead modeling for design and performance prediction," Geomechanics and Tunnelling, vol. 1, no. 1, pp. 18-28, 2008.

[26] O. Arnau and C. Molins, "Three dimensional structural response of segmental tunnel linings," Engineering Structures, vol. 44, pp. 210-221, 2012.

[27] H. Ligata, A. Kahraman, and A. Singh, "An experimental study of the influence of manufacturing errors on the planetary gear stresses and planet load sharing," Journal of Mechanical Design, vol. 130, no. 4, Article ID 041701, 2008. 


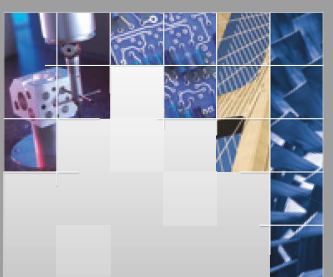

\section{Enfincering}
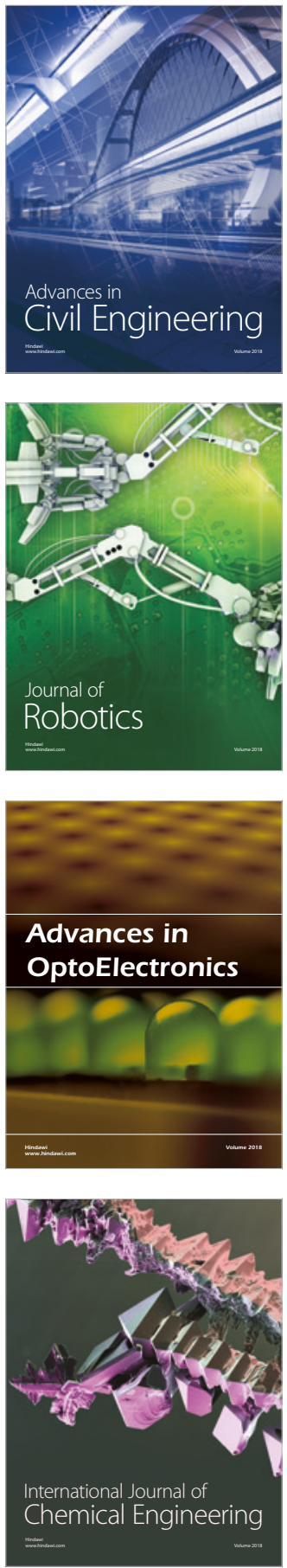

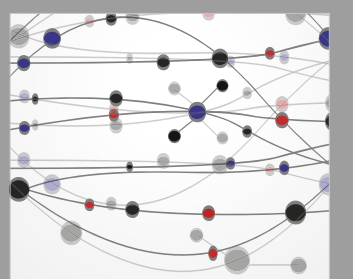

\section{Rotating \\ Machinery}

The Scientific World Journal

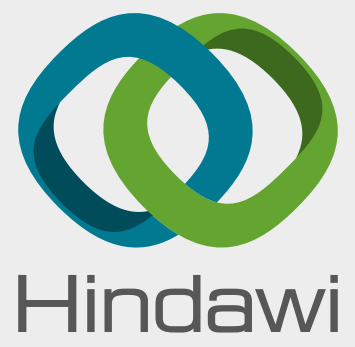

Submit your manuscripts at

www.hindawi.com
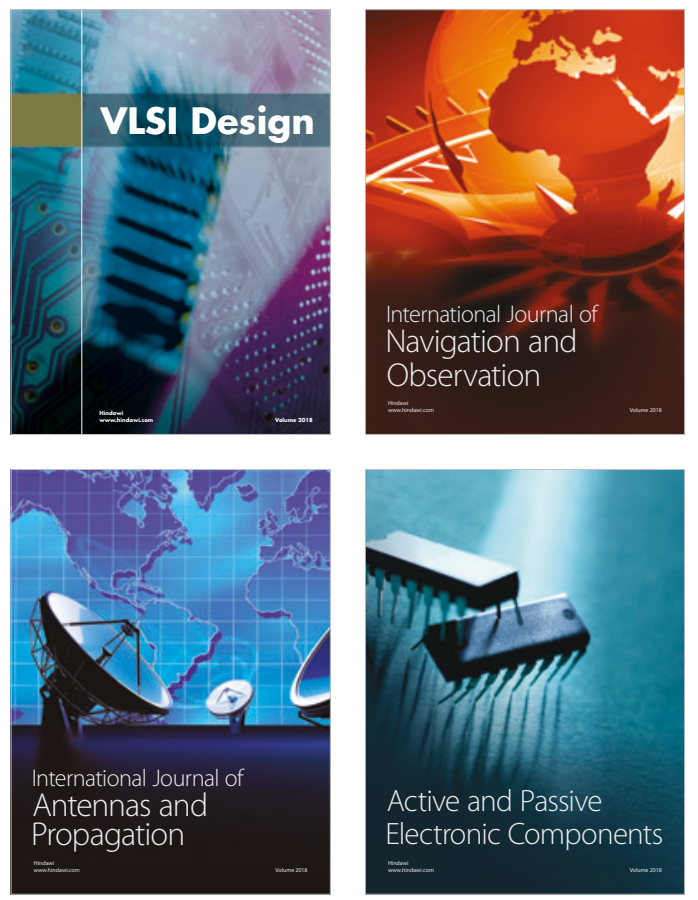
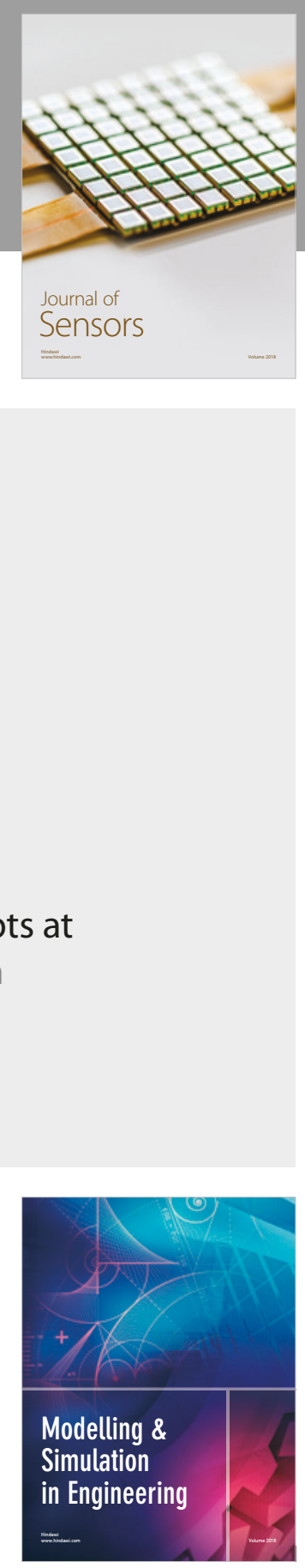

\section{Advances \\ Multimedia}
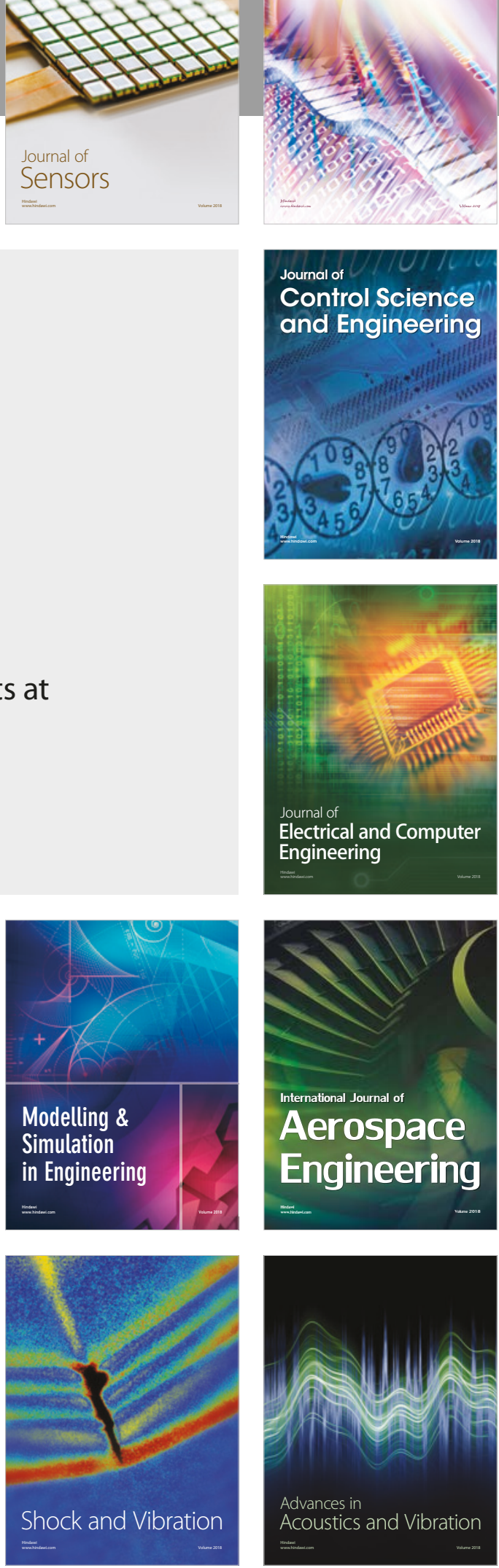